\title{
PORTUGUESISMOS EN DOS DIALECTOS ESPAÑOLES EN LUISIANA *
}

\author{
Samuel G. Armistead \\ University of California, Davis \\ A la memoria de José Pérez Vidal
}

De los tres dialectos españoles del estado de Luisiana que han sobrevivido hasta nuestros dias, dos tienen su origen en una iniciativa de colonización canaria de finales del siglo xvin ${ }^{1}$. Estos dialectos de origen canario son, por un lado, el isleño, que siguen hablando unos 200 individuos -quizás ya algunos menos - de unos sesenta o más años, residentes en cinco aldeas en la parroquia de St. Bernard, a unas 35 millas al sureste de Nueva Orleans, y, por otro, el bruli, que se hablaba hasta hace algunos años en los alrededores de Donaldsonville (parroquias de Ascension, Assumption e Iberville), a unas 60 millas al noroeste de Nueva Orleans ${ }^{2}$. El dialecto isleño aún es una len-

* Ante todo me complace agradecer — de todo corazón- a los colegas y amigos que, con su generosidad y erudición, me han ayudado en la preparación de estos materiales. A Manuel Alvar, María Angeles Álvarez Martínez, Manuel da Costa Fontes, Pilar García Mouton, Hiram F. Gregory, Antonio Sánchez Romeralo, Maximiano Trapero y Ramón Trujillo va mi más sincero agradecimiento. Huelga decir que sin la generosa intervención de mis amigos Irvan Pérez y Alfred Pérez, de Poydras (St. Bernard Parish), éste y otros varios trabajos míos sobre el dialecto isleño y su literatura tradicional hubieran sido imposibles de realizar.

1 El tercer dialecto, del que aquil no nos ocuparemos, es el adaeseño, recordado aún por algunos ancianos en aldeas y alquerías en dos áreas del noroeste del estado. Trátase básicamente de un dialecto mejicano aislado y arcaizante. Véanse mi artículo (con $\mathrm{H}$. F. Gregory) y los de Stark y Lipski ( Río Sabinas»). Sobre la supervivencia del español en Luisiana, téngase en cuenta mi artículo, «Tres dialectos».

2 Sobre el dialecto isleño, sigue siendo de importancia fundamental la monograffa pionera de MacCurdy (abrev.: M); sobre el dialecto bruli, la «Word List» de MacCurdy es, por ahora, lo único que tenemos. La voz bruli refleja la pronunciación en inglés luisianense del francés cadjin bralé 'quemado', aludiendo a los matorrales quemados y desbrozados para establecer las granjitas de los colonizadores españoles. Sobre la historia de los canarios en Luisiana, el libro de Din es imprescindible; para los brulis específicamente: págs. $64-83,96-104,107-114,135-143,164-176$. 
gua viva y los que lo hablan dominan, en toda su complejidad, un léxico capaz de representar las más recónditas facetas de lo que fue la cultura tradicional de esta comunidad de pescadores y cazadores de caimanes y ratas de agua en el delta del Misisipi ${ }^{3}$. Muy distinto ha sido el destino del dialecto de los brulis, agricultores en escala menor, residentes de un aislado islote lingüístico rodeado y profundamente influido por el dialecto francés luisianense o cadjin. En los años 70 y 80 aún llegué a entrevistar a los últimos hablantes - los "Antonio Udina"- de tan singular dialecto, que ya se encontraba in articulo mortis ${ }^{4}$. Mis informantes, ancianos de unos ochenta y noventa años, hablaban con dificultad, acudiendo al inglés a cada momento y titubeando respecto a la pronunciación y la morfología de su dialecto. Al intentar localizar algunos de mis antiguos informantes en 1991 —en compañía de Manuel Alvar - dimos con un solo individuo, quien ya durante mis encuestas anteriores no podia $\longrightarrow$ no quería - hablar y sólo recordaba a trancas y a barrancas algunas palabras sueltas ${ }^{5}$. Aún puede que haya "por ahi" alguna persona que siga recordando el español bruli, pero hoy por hoy me resigno, con tristeza, a dar por extinguido el dialecto ${ }^{6}$.

Mis encuestas en Luisiana - realizadas durante múltiples viajes de campo entre 1975 y 1988 - tuvieron como finalidad primordial recoger todo vestigio de literatura oral hispánica que pudiera haber sobrevivido en aquellas comar$\operatorname{cas}^{7}$. Pero a la vez, en todas mis encuestas, siempre procuraba grabar cualquier material de interés lingüístico que se pusiera a mi alcance y además,

3 Uitimamente, John M. Lipski ha estudiado el dialecto isleño desde el punto de vista de la muerte de las lenguas (The Language). Sin duda, según he experimentado también, hay muchos isleños que ya se encuentran en el trance de perder su lengua ancestral y que hablan - titubeando - un español vestigial. Con mucho acierto, Lipski ha investigado las implicaciones lingüísticas y culturales de este fenómeno. Por otra parte, quienes aún cultivan el dialecto isleño lo hablan con toda facilidad, manejando una riqueza léxica asombrante. Por lo tanto, la situación lingǘlstica de los isleños contrasta notablemente con la de los brulis y adaeseños.

- Recuerdo al último dalmático-hablante entrevistado a finales del siglo pasado por Mateo Bartoli. Sobre el ocaso del dialecto bruli, véase Manuel Alvar, «La última voz», $A B C$, domingo 4-X-1992, pág. 66.

5 Sobre las encuestas con Alvar, véase su hermoso artículo, «Encuestas en Estados Unidos*, págs. 277-278.

- En 1959, MacCurdy ya daba un pronóstico pesimista: «Spanish is a doomed language in the brulis» ( Word List», pág. 548).

7 Hasta el día de hoy, he grabado unas setenta y ocho horas de materiales entre isle ños y brulis; 10 de estas cassettes corresponden a informantes brulis, el resto a isleños. Los materiales adaeseños constituyen una serie aparte de unas veintidós horas. Sobre los trabajos en Luisiana, véase mi libro, The Spanish Tradition (abrev.: ST), y también mis articulos sobre romances, adivinanzas, corridos y juegos infantiles. Para los pobres restos de literatura oral entre brulis y adaeseños, nótese mi arficulo, «Vestigios». Pueden contrastarse tan exiguos espigueos con el abundante repertorio isleño: décimas, corridos, romances, cantos líricos, rimas infantiles, adivinanzas, refranes, cuentos tradicionales y relatos personales (editados en $S T$ ). 
dándome cuenta de la situación de los dialectos, tomaba la iniciativa para buscar todos los testimonios lingüísticos que pudiera recoger.

Entre los materiales isleños recogidos - y en grado menor entre los brulis (dada la extremada decadencia de aquel dialecto) - resultaba impresionante la presencia de una variedad de voces de origen portugués ${ }^{8}$. Se podría pensar $-\mathrm{y}$ he pensado- en la posibilidad de alguna presencia de inmigrantes portugueses venidos directamente de Portugal entre los Acebedo, Acosta, Alfonso, Brito, Corvo, Estévez, Falcón, Méndez, Meneses, Pinto, Serpa(s), Silva, Sosa y Viera hoy residentes en las comunidades isleñas ${ }^{9}$. Según veremos, semejante hipótesis carece de fundamento.

En lo que sigue, van en primer plano las voces isleñas y brulis de seguro (o probable) origen portugués ( $u$ occidental). Para el isleño, me baso en mis propias encuestas de campo y en la monografía pionera de MacCurdy (abrev.: M). Con la finalidad especifica de identificar portuguesismos adicionales, he realizado últimamente una serie de encuestas telefónicas $(8,13,19,27$ de ju-

8 En sus reseñas de la monografía de MacCurdy, Pérez Vidal ya tomó nota de la presencia de un «notable número de portuguesismos que se usan corrientemente» en el dialecto isleño e incluye la lista siguiente: «caquero, cambado, cambar, emborrallado, escanillo, escarranchado, fechadura, fechillo, ferruje, fondaje, jaito (jeito), liña, morianga, pilla, quejo, rente, safadon (Revista de Historia, pág. 424). Por otra parte, con alguna excepción, Pérez Vidal no aprovecha las voces luisianenses en su exhaustivo estudio de los portuguesismos canarios (PV). Con referencia a la susodicha lista, MacCurdy no registra el portuguesismo canario caquero 'sombrerillo viejo' (Lugo, pág. 75 ; Millares) y dudo que se haya usado tal expresión en el dialecto isleño. Ninguno de mis informantes la conoce. Respecto a escarranchado y safado, no me convenzo de que sean portuguesismos de tradición directa en Canarias.

- Entre los brulis, hay Acosta, Corbo, Falcón y Serpas. Todos estos apellidos isleños y brulis (menos el isleño Faba) - junto con otros muchos de segura o posible ascendencia portuguesa- constan en las listas de pasajeros de los primeros colonizadores canarios de Luisiana (1778-1783). Tengamos en cuenta los siguientes: Abreu, Acebedo, Acosta, Alfonso, Almeida, Brito, Corvo, Chávez, Estévez, Falcón, Fonte, Mateos, Melo, Méndez, Meneses, Orta, Paez, Perera, Pimentel, Pinto, Silva, Sosa, Viera, Zerpa (Din, págs. 209-235). Tales datos se pueden comparar con la rica documentación onomástica canaria reunida e interpretada por Pérez Vidal (PV, 13-69). (Nótese también el artículo de Bonnet.) Al tener en cuenta además los muchos apellidos ambivalentes - tan castellanos como portuguesesque, mediante la documentación temprana, podemos comprobar a ciencia cierta pertenecían a familias de origen portugués arraigadas en las Islas, conviene encarecer aún más el sustrato lusitano de los colonizadores canario-luisianenses del siglo xvIII. La influencia portuguesa en Canarias dura desde el siglo xiv hasta el mismo siglo xvirI (en distintos grados de intensidad, claro está). Es inadmisible, como pretende Alvarez Delgado, argüir que los portugueses que llegaban a Canarias ya estaban españolizados («Notas», págs. 232-234). Muy al contrario, en Canarias se habló y se escribió en portugués durante mucho tiempo y la influencia lusitana en las Islas es, como han demostrado Pérez Vidal y otros, de importancia fundamental. Sobre diversos aspectos de la presencia portuguesa en las Islas, pueden verse, p. ej., los artículos de Hardisson, Lozoya, Pires de Lima, Ricard. Creo que el primero en evaluar sistemáticamente los préstamos portugueses en el español canario ha sido Max Leopold Wagner - trayendo a colación sus vastos conocimientos de la lingüfstica románica - en su reseña del Léxico de los Millares (págs. 82-83). Después, la edición que realiza Pérez Vidal de la Colección de voces de Lugo marca un gran paso adelante. 
lio 1992) con el Sr. Irvan Pérez, de Poydras (St. Bernard Parish), cuya intervención en mis encuestas anteriores ha sido de importancia fundamental. También agradezco de todo corazón la indispensable ayuda del Sr. Alfred Pérez. Para el dialecto Bruli, sigo casi exclusivamente la "Word List" de MacCurdy, ya que mis propias diez horas de cassettes de la región de Donaldsonville aún están sin transcribir ${ }^{10}$. En cada caso, pongo mis propias definiciones (en español), seguidas (entre paréntesis y entre comillas) de las aclaraciones de mis informantes (en inglés o en isleño); a continuación, pongo las definiciones de MacCurdy (en inglés).

Tras el signo /, pongo en primer lugar los testimonios de la indispensable monografía de José Pérez Vidal sobre Los portugueses en Canarias (abrev. : $\mathrm{PV})$, seguidos de los del monumental ALEICan. A continuación, se hace constancia de una serie de artículos de Pérez Vidal y luego de las citas pertinentes de varios glosarios y estudios del español de Canarias.

En tercer lugar, tras //, cito las voces portuguesas correspondientes, con definiciones del Dicionário de Martínez Almoina. También he consultado en cada caso el gran Dicionário de Morais y a veces además los de Figueiredo y Taylor. A continuación, pongo las voces análogas en gallego (según el Diccionario de Carré), seguidas — con finalidades comparativas- de cualquier testimonio pertinente que he podido localizar en asturiano y leonés $\mathrm{y}$, a veces, también en el español de Salamanca, de Extremadura y de Hispanoamérica. En lo que se refiere al origen inmediato de los "portuguesismos" u "occidentalismos" canarios, conviene tener presente la atinada observación de M. Alvar: "Los préstamos de voces que existen en gallego y en portugués es mucho más probable que procedan, en Canarias, de Portugal (metropolitano o insular)" (Alvar, pág. 92). Durante mis encuestas, incluso he tenido el placer de charlar un poco en gallego con un pescador anciano residente en Yscloskey (La Habitación) y una de las canciones tradicionales que recogí en Delacroix (La Isla) es indudablemente de origen asturiano ( $S T, 86-88)$. Pero tales factores son casos aislados y de carácter tardío y no habrán tenido ninguna trascendencia en la formación del dialecto.

Lo recogido en las páginas que siguen se presenta como un mero suplemento a los masivos materiales canarios reunidos en $\mathrm{PV}$, al que, en todo momento, se ha de acudir, dada la riqueza de documentación adicional allí consignada.

10 Proyecto editar un glosario del dialecto bruli, acompañado de los pocos textos coherentes que pude recoger. Para alguna muestra, véanse, por ahora, mis «Vestigios». 
adivina 'adivinanza' (ST, 109 y sigs.); devina 'riddle' (M); en cambio, bruli : devinansa ("Word List"). / adivina, adiviña, diviña (PV, 120-121): Hoy en día en Canarias predomina adivina sobre adiviña. Creo, con Pérez Vidal, que adivina, en si, no ha de ser un portuguesismo, sino meramente un derivado post-verbal de adivinar, pero en la forma breve adivina (contra adivinanza) se sugiere quizá alguna influencia portuguesa, sobre todo dándose la presencia en Canarias del portuguesismo adiviña. Véase también Navarro (adivina, divina). // adivinha; gall. adiviña.

ajeita'o 'mañoso': "tiene buen jeito"; "está malajeita'o". / ajeitado 'mañoso'; desajeitado 'que no tiene jeito' (PV, 112, 114); también “Comportamiento”, pág. 237. // ajeitado 'puesto adecuadamente'; 'adestrado, acostumado a certo trabalho; que tem bom jeito' (Morais); 'que tem boa aparência' (Figueiredo); gall. axeitado 'arreglado; puesto en buena disposición'. Véase jeito, jeitoso (infra).

alfinel 'alfiler'; finel derecha 'straight pin'; finel de pañal 'safety pin' (M); bruli finel de pañal 'straight pin'; finel de toilette 'safety pin' ("Word List”). / alfinel (PV, 151; “Analogía”, págs. 74-75; “Arabismos”, págs. 247, 252-253). Nótese también la planta llamada alfinelera (PV, 180; Viera, s. v. pico de cigüeña; ALEICan, lám. 303). // alfinete 'alfiler'; gall. igual. La voz canaria nace del cruce de esp. alfiler + port. alfinete, según lo demuestra PV. El j.-esp. oriental tiene la forma portuguesa: alfinete 'Stecknadel' (Wagner, Beiträge, 136; ahora reimpreso: Sondersprachen, III); los sefardies de Rodas, según me acuerdo, decían (contra los entrometidos): "Alfinete, que en todo se mete"; en Marruecos consta alfiler 'grande broche de oro afiligranado'; pero también se da alfilete (Benoliel, pág. 560), forma que refleja un cruce luso-español análogo al de la voz canaria. Para la etimología, véase $D C E C H$, s. v. alfiler.

andoriña 'golondrina'. En el ámbito geográfico isleño, puede referirse a una variedad de especies: Peterson, págs. 164-167. / PV, 133 ('persona vivaracha'), 177 ('golondrina'), 237 ('cabra de color oscuro entero y de cuernos largos y muy abiertos'); ALEICan, 306: golondrina = andoriña (en todas las islas; compite con golondrina en GC); también Alvar; García Mouton; Lugo; Llorente (I), pág. 8; Navarro; Viera. También consta Andoriñas en la toponimia canaria (PV, 313: “Toponimia”, pág. 263). En ALEICan, 317 : murciélago $=$ andoriña o andoriña de ratón (únicamente en dos puntos: $\mathrm{Hi} 1$ y 10). Alvar explica la transferencia semántica como huella de una tradición folklórica: En un cuento tradicional catalán, "Dios y el demonio decidieron crear sendos pájaros hermosos; a Dios le salió una golondrina y al diablo, un murciélago", mientras que en el Brasil se califica al murciélago de passarinho do diabo ("Originalidad", págs. 236-237; Sanchís Guarner, pág. 112; Câmara Cascudo); en La Segarra (Alicante): ausell del demoni (Sanchís 
Guarner, pág. 94); en algunos dialectos italianos igualmente se le dice auciel $d u$ dmone, aciidde du demmonie 'uccello del demonio' y formas afines (Eggenschwiler, pág. 178; mapas 7, 9, 10, 12: núm. 719); también en Marruecos, se supone que "el murciélago es obra del diablo; por eso está castigado con volar sólo de noche” (Ibn Azzuz, pág. 39). Las formas herreñas dan fe de la capacidad -al parecer casi ilimitada - que posee el murciélago de inspirar la imaginación popular. Nótense las monografías de Sanchís Guarner y Eggenschwiler (citadas por Alvar). Véase también el resumen de las asociaciones semánticas, más una densa documentación de diversísimas creencias populares, en Bächtold-Stäubli y Hoffmann-Krayer (II, s. v. Fledermaus); más datos sugerentes: Erich y Beitl; Radford y Hole; Opie y Tatem ${ }^{11}$. La asociación del murciélago con toda suerte de pájaros es muy frecuente: En catalán consta aucell de nit (Sanchís Guarner, pág. 94) y en gascón, auzet de nweit; en Italia también hay abundantes formas dialectales con el sentido de 'uccello di notte' y más especificamente 'rondinella (di notte)' (Eggenschwiler, págs. $29,118,133,144,177-178,258,263-264$ et alibi). En rum., liliac se relaciona con numerosas voces eslavas y balcánicas que, en algunos casos, significan 'murciélago' y en otros señalan diversos pájaros, incluso en checo lelek 'variedad de golondrinas' (Cioranescu); en ruso, lelek corresponde a la chotacabras. En Marruecos también, al murciélago se le dice tị el-lil 'pájaro de la noche' y se le atribuyen numerosas creencias (Westermarck, II, 327329 et alibi). // andorinha 'golondrina'; gall. anduriña (Ríos Panisse, II, 24, 39-40; Whinnom, núm. 350).

arco la vieja 'arco iris'. / arco (de) la vieja (PV, 153-154; ALEICan, 762: arco iris: en todas las islas, menos Go y Gs); también Alvar; García Mouton. // arco-da-velha 'arco-iris'; "diz-se das coisas ou factos espantosos ou inverosimeis : «Foi uma coisa do arco-da-velha»" (Morais; Figueiredo); gall. arco da vella; ast. arco da veya, ... la vieya, ... la viecha, ... das viechas (Acevedo; Rz.-Castellano, Contrib., pág. 23); leon. arco la vieya (Casado Lobato, 36). Sobre la voz y sus implicaciones, véanse las observaciones cruciales de Alvar, "Dialectología", pág. 22, y García Mouton, "El arco iris".

arranchar, ranchar 'arreglar, reparar; atender'; 'to mend, fix, repair' (M); "Y cuando teníamo que arranchar lą trampą, a cá dọ díą, él cogía una randa y yo cogía otra. Y él ranchaba una randa y yo ranchaba la mía" (ST, $158)$; en una décima: "Y con esto me despido, / tengo troles que ranchar;

11 Como muestra de una inagotable Volksphantasie, consten, entre otras diversísimas asociaciones semánticas, los tipos souris volante, crapaud volant, topuccello, uccello-ratto, mezzosorcemezzuccello, mezzaratta, ratavoliva, rattapinnata, gattapennata, gattambulatore, sorcio vecchio, sorcio orbo, sorcio di notte, topo alato, scorpione, uccello della morte, etc. (Eggenschwiler, págs. 263-266; mapas 8: núm. 558; 10;19: núm. 5; et alibi), amén de los chauve-souris, pipistrello, rat-penat, murciélago y morcego académicos, que tampoco se quedan atrís en lo que se refiere a su notable contenido imaginativo. 
/ y esta zafra que viene / verán lo que va a pasar" (MacCurdy, "Los «isleños»", pág. 111). MacCurdy deriva bruli desranchar 'to disconnect, disarrange' del fr. déranger. / arranchar 'equiparse, reponer fuerzas; disponer' (PV, 102); también "Marineras"; Navarro. // arranjar 'arreglar, componer; disponer'; gall. arranxar 'arreglar, ordenar, componer'. No es difícil que, en Luisiana, el portuguesismo canario se haya reforzado con el fr. cadjin arranger 'to repair, fix, mend, arrange' (Daigle) o bien, más tarde, con el ingl. arrange 'ordenar'. Téngase en cuenta también, en cast., la voz especializada y marinera arranchar (Garasa).

arrumbado 'debilitado; arrastrándose' ("dragging, no energy"). / arrumbado 'amodorrado, aletargado' (PV, 125); también "Marineras". // arrombado 'doente' (Madeira: PV, 125); arrombar 'vencer, desbaratar, abater; derribar' (Morais); 'arruinar, vencer' (Figueiredo).

barriga de la pierna 'parte gorda de la pierna'. / PV, 95; ALEICan, $500 \mathrm{n}$. // barriga da perna 'parte mais grossa, curva, da região posterior da perna' (Morais).

bichento 'lleno de bichos'. / bichento 'que tiene bichos' (PV, 204). // bichento 'que tem bichos nos pés'; "Diz-se das frutas atacadas pelas larvas de insectos frutivoros" (Morais). Véase bicho (a continuación).

bicho 'insecto, oruga' ("bug"); se usa sobre todo para designar distintos tipos de oruga: bicho pelú, bicho roble, bicho wanconú ("red caterpillar"; muy venenosa, que se encuentra en el árbol bois inconnu); también bicho moŝco 'larva del mosquito'; bichento 'lleno de bichos' (p. ej.: "the meal is full of bugs"); bruli bicho pelú 'caterpillar' ("Word List"). Sobre fr. cadjin bois connu, o mejor dicho bois inconnu, un árbol que alcanza proporciones gigantescas (ingl. hackberry tree: Celtis occidentalis L.), véanse Read, págs. 12-13; McDermott, pág. 28; y para el árbol: Harrar, págs. 249-251. / bicho 'gusano; insecto; piojo; el Bombix mori o gusano de seda' (PV, 174, 204-205, 250-251); bicho negro 'cochinilla de la humedad' (Alvar); bicharango (Millares; Navarro); bichillo 'lombriz que se cría en la seba podrida de la orilla del mar'; bicho pelúo 'cierta lombriz' (Navarro); Viera (s. v. gusano). // Claro que bicho pasó del port. al cast. hace siglos $(D C E C H)$, pero parecen del todo justificados los argumentos de Pérez Vidal en favor de su origen portugués en las Islas: "Su vitalidad en Canarias -arraigo, riqueza semántica, derivados- apoya su portuguesismo" (PV, 174). Creo, además, que se ha de pensar en el portuguesismo semántico de bicho, tanto en Canarias, como en Luisiana. En cast., el sentido académico es muy general: 'cualquier sabandija o animal pequeño' (DRAE). En portugués, en cambio, se señalan sobre todo los insectos y gusanos: "nome que se dá a qualquer animal; díz-se mais especialmente dos insectos e tambem dos vermes" (Morais); 'any unspecified animal, espec. bugs, insects and worms' (Taylor), que es 
exactamente el caso del español canario y de los dialectos de Luisiana. En Hispanoamérica también bicho tiene connotaciones más generales: 'dícese de cualquier animal extraño o poco común, raro, curioso o extravagante' (Santamaría; Morínigo), no excluyendo, por cierto, las sabandijas, insectos y orugas.

bobanco 'tonto de remate' ("extra foolish, plenty"). / bobanco 'bobalicón, bobo' (PV, 113); bubango, buganga, bugango 'especie de calabaza' y de ahí 'necio, bobo, tonto, mentecato', como en cast. calabacin (PV, 199-200); ALEICan, 229: bubango (general en todas las islas menos Gs; esporádico en Fv y Lz); “Analogia”, págs. 62-63; “Comportamiento”, pág. 242; García Mouton; Guerra (s. v. boango); Llorente (I), pág. 11; Navarro (s. v. bubango). Compárese también abobancado 'abobado, flojo' (PV, 111). // moganga, mogango 'variedad de calabaza'; 'variedade de abóbora menina' (Morais); también bogando, boganga, bogango (Morais; PV, 199-200).

cabucar, cabuquear 'devanear; chochear' ("like an old person, talking out of their mind; off your head"): "Está cabucando". / cabucar 'equivocar, confundir' (PV, 113). // incaboucar, incabucar (dialectal; PV, 113); gall. cabucar 'equivocar, confundir'.

cambado 'torcido'; 'bent, crooked' (M); también se usa figurativamente: "dishonest" (como en el slang anglo-americano: crooked). Nótese la comparación popular: más cambado que un politisiano 'más tramposo que un politico'. / ALEICan, 353: cuernos bajos = cambao $(\mathrm{GC}, 10) ; 1019$ : alcayata $=$ tacha cambada $(\mathrm{Lz}, 1) ; 1093 \mathrm{n}:$ curvo, doblado = cambao; Alvar ; Lugo; Navarro. // cambado 'torcido por un lado; encorvado; patizambo'; 'que tem pernas tortas' (Figueiredo); gall. 'estevado; arqueado; que tiene las piernas torcidas en arco: argent. cambado 'el que tiene las piernas torcidas' (Santamaría).

cambar 'torcer; doblar; encorvar'; 'to bend, twist' (M); igual en bruli ("Word List"). / ALEICan, 1093n: doblar = cambar; Guerra; Lugo; Millares; Navarro. // cambar 'encorvar; tambalear'; gall. 'arquear, curvar'; andar cambado 'cojear'; se dan voces afines en ast., leon., salam. (DCECH, s. v. cama) ; venez. cambar 'combar, curvar, encorvar' (Santamaría). En Canarias, puede ser de origen portugués u oriental, pero consúltese DCECH.

castrar 'curar con sal' (respecto a las pieles de ratas de agua) ("to cure, salt down"). / castrar (la piel) 'espigar, irritar por el calor o el frío' (PV, 126). // crestar 'chamuscar, quemar ligeramente; tostar; abrasar; quemar'; también: 'secar por efeito do frio ou do calor' (Morais; compárese Figueiredo). Creo que la extensión semántica de la voz portuguesa explica - quizás- la especialización del portuguesismo en Luisiana.

corujo 'búho' $(S T)$; curujo 'owl' (M). Se aplica a cualquier búho gran- 
de, a diferencia de la pequeña sueta ( $<$ fr. chouette) 'screech owl' $(S T ; \mathrm{M})$. Nótese la décima: "Había un corujo aposa'o / en el monte Florisón. / Cuando él supo que yo iba, / dio un volido pa Torreón. / Y vino el corujo y me dijo: / - ¿ Ha visto una cosa asina? / i El castigo que ne dan por comerno lą gayinas!" (ST, 37). En bruli se dice sueta 'screech owl' ("Word List"), pero, que yo sepa, no existía corujo. / ALEICan, 305: lechuza = coruja (siempre fem.); se da en todas las islas; compite con lechuza, sobre todo en GC (también Fv, Lz); Alvar; Garcia Mouton; Lugo; Navarro; Viera (s. v. lechuza). Nótese, por otra parte, corujo 'el coco, fantasma para asustar a los niños' (Alvar). Llorente (I) lo da como occidentalismo, notando la presencia de coruja en Extremadura occidental y en el noroeste de Huelva y de Córdoba (pág. 30). En las tres áreas es perfectamente posible que la voz portuguesa haya sido adoptada con independencia respecto a Canarias. Nótese en Extremadura coruha 'lechuza ; mujer de mal carácter, mala e hipócrita'; coruha aceitera 'lechuza' (Viudas Camarasa); porque se cree que beben el aceite de las lámparas en las iglesias (Sánchez Pérez, pág. 174). // coruja, corujo; gall. curuxa (Corral Díaz); curuxó (Ríos Panisse, II, 36); curuxo también designa una variedad de peces (Ríos Panisse, II, 430); ast. coruxa; curuxa; coruxu 'lechuza' (Vigón; Conde Saiz; Neira Martinez). Claro que curuja también se da en cast. (DCECH, s. v. acurrucarse), pero junto a los demás portuguesismos, creo que podemos afirmar que, en las hablas canarias, la voz puede ser de origen portugués o, por lo menos, occidental. Nótese Whinnom, pág. 61 (núms. 307-308) ${ }^{12}$.

chovisnear 'lluvia ligera, pero constante' ("light but steady rain"). / Cfr. chovisquear 'lloviznar'; churivisquear, chuviscar, chuvisquear, chuviznar (PV, 155-156; "Lluvia", págs. 190-192). // chover + cast. lloviznar (favorecido en otras formaciones afines). Nótese gall. chuviñar = barrallar 'lloviznar' (Otero).

chumasero 'mazo o herramienta con que se calafateaba los barcos' ("el maso con que chumasavan las topas, el jierro de garafateá”); chumasar. / chumacera 'pieza encajada sobre la borda del bote y en la que se inserta el tolete' (Alvar; véase el dibujo 43; para el tolete [b]). (Pero el tolete, en este sentido, se dice en la isla de San Bernardo pichoco; las escalameras ("oarlocks") se llaman estrobos.) En ast., chumazu tiene este mismo sentido, pero se aplica a la terminología del carro de bueyes (Conde Saiz, págs. 292-293:

12 Entre los judíos del norte de Marruecos, se dice encoružado 'encogido, arrugado, resequido, desmedrado'. Según explica Benoliel: «Viene esta palabra de ... [la] acción de la coruja, lechuza, sobre los niños, la cual consiste en turbarlos con su grito, y en hacerlos ahilarse con su presencia o proximidad» (pág. 59). También constan encoružamiento y encoružarse. Sobre creencias norteafricanas referentes a los búhos (y los murciélagos) y específicamente entre los judíos, véanse Armistead y Monroe, «Albas», págs. 185-186; Armistead, «Américo Castro», págs. 79-80. 
dibujo: El karru). // Como se ve, el sentido de chumacera en Canarias es completamente distinto del de la voz isleña; con el significado de la forma canaria, chumacera ya consta en castellano desde 1675 (DCECH), procedente, claro está, del portugués (chumaceira 'pieza de metal o madera, con una muesca en que descansa y gira cualquier eje de maquinaria; mar. chumacera'; compárese Figueiredo). El término isleño, aunque sea semánticamente especializado, en cuanto sugiere el proceso de rellenar - calafatear el barcoqueda muy cerca del campo semántico esencial del port. chumaşo 'almohadilla ; plumón; compresa; hombrera para la ropa, hecha con guata; volumen; hinchazón'; 'padding, stuffing, wadding (of cotton, straw, feathers)' (Taylor; más datos: Figueiredo). Nos podemos confiar, según creo, en su origen portugués directo en Canarias y Luisiana, con independencia del portuguesismo castellano. Compárese port. enchumaçar-se 'encher-se como com chumaço' (Morais).

chumbo: estar medio chumbo 'estar medio borracho'; véase también enchumbarse (infra). / chumbo 'llovizna persistente con niebla' (PV, 155; "Lluvia”, pág. 190). // chumbar 'emplomar; pop. embriagar'. Véase $D C E C H$, II, $407 b$. Para la asociación de llover con emborracharse, compárese el verbo isleño chipiar (está chipiando "real light rain"), con los versos siguientes de una décima popular: "Máŝ alegría fue pa la gente, / cuando vieron a Toñito, / con cinco dollars demás / y venía medio chipo" (ST, 3536). Nótese la voz canaria, chipichipi 'llovizna suave pero persistente' ("Lluvia”, pág. 189).

devaso 'holgazán'; 'idler, loafer' (M). / debaso 'holgazán, gandul' (PV, 114); Millares; Guerra. // devasso 'libertino, disoluto, licencioso'; algo más cercano semánticamente a la voz canaria está devassar-se 'tornar-se lasso ou relaxado' (Morais); devassar 'tornar lasso; tornar relaxado, licencioso' (Figueiredo).

emborrayar 'ensuciar'; 'to soil' (M); emborraya'o 'sucio' (“smeared"); 'dirty' (M); bruli emborrallado 'dirty ; cloudy' ("Word List"). Me pregunto si en la segunda acepción, no habrá un cruce con emborregarse 'aparecer cirros en el cielo' (se emborregó el cielo esta mañana) (Alcalá Venceslada). / emborrallar 'ensuciar con borralla'; borrallo 'borraja, rescoldo'; borrallento 'sucio de ceniza mojada, enlodado' (PV, 143, 141); también "Comportamiento", pág. 230; Lugo (s. vv. borrallo, emborrallado; emborrallar). // emborralhar 'encenizar, cubrir de ceniza'; también 'sujar' (Morais); -se 'ensuciarse, mancharse'; gall. emborrallar 'ensuciar, manchar'.

empate 'cuerda con un lazo, con que se ata el cebo [la carná] al palangre para pescar cangrejos [jaibas]' ("string to tie bait [to the line], with a loop where you put the bait"); se dice empatar. / empatar 'sujetar el anzuelo al hilo' (PV, 274); ALEICan, 847, n. : empatá 'sujetar el anzuelo al sedal' (Tf, 
2); empate 'acción y efecto de empalmar' (PV, 274); ALEICan, 111, n.: empate 'trozo añadido al timón'; otros sentidos (menos convincentes en lo que se refiere a su origen portugués): PV, 195, 296-297; ALEICan, 111: añadir, alargar = empatar (LP, Go, Hi, Tf, GC, Fv 3) ; "Marineras"; Alvar; Llorente (I), pág. 38. // empatar 'fixar (o anzol) à linha' (Morais); 'prender [anzóis] à linha de pesca com un nó que chamam empate' (Figueiredo); empate 'nó com que se fixa a linha de pescar; a parte do anzol onde se fixa a linha de pescar' (Morais; Figueiredo). La coincidencia semántica con las formas canarias e isleñas es tan exacta que, en este caso, no podemos dudar del portuguesismo de empate y empatar, que, por otra parte, se conoce con otros significados en cast. desde el siglo xvII, por lo menos, y está muy difundido en Hispanoamérica ( $D C E C H)$.

empayar 'amontonar (como paja)': "teníano que secála [la varva], tendęlla que se secara y empayar, ponerla que se pusiera negra" $(S T, 160)$. Se trata aquí (y también en el caso de empayorar) de la cosecha de una planta parasítica que en inglés se llama Spanish moss; fr. barbe espagnole (Tillandsia usneoides). / No dispongo de documentación canaria. // empalhar 'empajar; cubrir o forrar de paja'; 'recolher em palheiro (a palha)' (Morais; Figueiredo).

empayorar 'amontonar (como paja)'; payorar: "Y teníanq que payorar esa varva: pillą, pillą 'e varva ... mi hermano jasía, como un parque, tú sabę, asina, de tablą y metía la varva ahí adrento y la empayoraba, como uŝté jase, la paja" (ST, 159-160). / No dispongo de documentación canaria. // empalheirar 'recoger en el pajar o en la pajera; empajar'; 'recolher em palheiro (a palha)' (Morais; Figueiredo).

empillar 'amontonar' (“pile up”). / empillar 'apilar' (PV, 251-252). // empilhar 'empilar, apilar, amontonar; acumular ; apiñar'. Véase pilla (infra). enchumbarse 'empaparse' ("get wet, get soaked"); véase también chumbo (supra). / enchumbarse 'mojarse intensamente'; enchumbar 'mojar, ensopar, empapar' (PV, 297); chumbar 'lloviznar de modo persistente'; chumbo 'llovizna persistente con niebla' (PV, 155); “Comportamiento”, pág. 245 ; "Lluvia"; Alvar; Guerra. // enchumbar 'ponerse muy pesado, por estar muy mojado' ; para más datos sobre la asociación de 'emplomar' y 'mojar' en portugués y en las hablas canarias: PV, 155. Consta en muchas regiones de Hispanoamérica: Cuba, Santo Domingo, Puerto Rico, Méjico (Tabasco), Colombia, Uruguay (Di Filippo; Malaret; Morínigo: Santamaría ; id., Mejicanismos). Véase $D C E C H$, II, $407 \mathrm{~b}$.

engasgarse 'atragantarse, atascarse' ("[food] goes down the wrong way"). / engasgarse 'atragantarse' (PV, 126); Lugo. // engasgar 'atragantar, tener algo detenido en la garganta; sofocar, ahogar, estrangular'.

engoyar 'arrojar cebo al mar para atraer a los peces'. / engodar 'atraer a 
los peces con cebo o engodo; engodo 'cebo que se arroja desmenuzado al mar con el único fin de atraer a los peces'; engode 'acción de engodar' (PV, 274-275); "Marineras"; Guerra; Lugo; Millares. // engodar 'cebar (para atraer)'; engodo 'cebo (para cazar o pescar)'. El portuguesismo canario se ha extendido a Hispanoamérica: Alvarez Nazario, págs. 144, 191-192.

ensiña 'árbol (de cualquier especie)'; enciña 'tree (of any kind)' (M); también se dice árbol, árbole $(S T, 153)$; esta última forma: ¿influida por el port. árvore? $\mathrm{O}$ bien puede tratarse sencillamente de un arcaísmo, como la - $e$ paragógica que encuentra Alvar en Roque de Bodegas, Tenerife ("Sociologia”, pág. 12). Para más sobre el fenómeno, véase ahora mi artículo sobre la $-d$ - paragógica. // azinha 'bellota'; azinheira 'encina'; anzinha, enzinha (Morais; Figueiredo; $D C E C H$, s. v. encina).

ensolla'o 'techo escarpado, abrupto' ("a steep, sloping roof"). / No sé si tendrá que ver con sollado (y afines) 'suelo', etc. (PV, 138; aquí, s. v. solla'o) o bien con suallera 'ladera de un barranco donde da el sol todo el dia' (PV, 172); "Comportamiento", pág. 247; Alvar, pág. 237. // soalheira 'solana'; ensoalhado 'cheio, banhado de sol'; o bien soalhado 'madeiramento para soalhar' (Morais; Figueiredo). Véase solla'o (infra).

escaniyo 'cajón'; escanillo 'drawer' (M). / escanillo 'gaveta pequeña' (PV, 143-144); Lugo. // escaninho 'escondrijo secreto de una caja'; 'pequena divisão dentro da caixa, gaveta, esconderijo, recanto' (Morais ; Figueiredo); también escanilho (PV, 144).

fecha 'solera' ("the first, main post [you put down to build a house]"); también 'la lanza del carro de bueyes' ("the tongue of an ox cart [carreta wey]"). / frechal 'solera; madero asentado de plano sobre cada una de las cuatro paredes de una casa; los cuatro frechales forman el cuadro que sirve de base y encaje a casi todas las demás piezas de la armadura del tejado' (PV, 135). // frechal 'viga que sirve de sostén a otros maderos'; 'cada uma das vigas horizontais sobre que se levantam os frontais de cada pavimento de uma casa' (Morais; Figueiredo); pero también fechal en Madeira y Azores $(\mathrm{PV}, 135)$; ésta y la forma isleña han sido influidas por el verbo fechar.

fechadura 'cerrojo; pomo, tirador (de la puerta)'; 'lock, doorknob' (M); bruli fechadura 'lock' ("Word List"). / PV, 134; ALEICan, 552: cerradura $=$ fechadura (LP, 1; Tf, 3; GC: varios puntos); Guerra ; Llorente (II), págs. 194, 214-215, n. 15. // fechadura 'cerradura'; gall. igual.

fechar 'poner el fechillo'. / fechar 'cerrar (la puerta, la ventana, los ojos)' (PV, ....); ALEICan, 551 (LP, Tf, GC); “Comportamiento”, pág. 240; Alvar; Guerra ; Llorente (II), págs. 194, 214-215, n. 15 ; Lugo (s. v. fechadura); Millares. // fechar 'cerrar con llave'; gall. igual; también se da en Asturias, Extremadura y en Andalucía (los dos últimos casos, como portuguesismo). Véase PV. 
fechillo 'picaporte; pestillo; pequeño pestillo o cerrojo (como para cerrar un baúl)'; 'bolt (of a lock); latch' (M); fechillo representa, obviamente, un cruce con pestillo. / fechillo 'pasador de hierro para cerrar (ventanas, puertas)' (PV, 134-135); ALEICan, 549: pasador de hierro $=$ fechillo (en todas las islas; alterna con fecho en LP); 994 : cerrojo $=$ fechillo (GC, Fv, Lz, Gs; junto con cerrojo y ferrojo); Alvar ; García Mouton; Guerra ; Llorente (II), págs. 194, 214-215, n. 15. // fecho 'cerrojo, aldaba, pestillo, pasador'; 'ferrolho ou aldrava de porta, janela' (Morais; Figueiredo); gall. fecho 'cerradura'.

ferrugiento 'oxidado; herrumbroso'; ferroyento 'rusty' (M); también bruli ("Word List"). / ferrugiento, ferrugento 'herrugiento' (PV, 298); “Comportamiento”, pág. 239; Guerra; Millares. // ferrugento; gall. ferruxento; ferrugente (Otero); ast. ferruyento, ferruñentu (Vigón; Canellada); firrunientu (Rz. Castellano, Aspectos, pág. 257): leon. ferruñentu (Alvarez, Babia, pág. 293).

ferruje 'oxidación; herrumbre'; 'rust' (M); también bruli (“Word List”). / ferruja, ferruje 'herrumbre, robín' (PV, 298); Alvar; Guerra; Lugo. // ferrugem 'herrumbre': gall. ferruxe; ferruša (Orense; y otras variantes gallegas: Krüger, Gegenstand., pág. 98, n. 1); ferruše (Taboada, Verin, págs. $69,78)$.

fondaje 'heces' (de cualquier sustancia); 'dregs' (M); también bruli ("Word List"). / fondaje 'poso, sedimento, heces' (PV, 150, 219); ALEICan, 159: heces $=$ fondaje, fondajo (sólo en un punto de Tf y tres de GC) y en el mapa 780: fango = fondaje (en un solo punto de Lz); "Comportamiento", pág. 233; "Léxico"; Guerra; Lugo. // fundagem 'sedimento, poso'; gall. fondaxe 'lo que queda en el fondo, fondillón'; $D C E C H$, s. v. hondo.

fonil 'embudo'; más corriente es lembú 'funnel' (M). / fonil 'embudo' (PV, 144, 219); ALEICan, 157, n.: fonil 'embudo (de bodega)' (LP, 30 ; Tf, 4, 40); "Léxico"; Alvar; Garcia Mouton; Guerra ; Llorente (I), pág. 41 ; Lugo. // funil 'embudo'; 'funnel' (Taylor); gall. igual. En Canarias, podria provenir directamente del castellano, donde, por otra parte, consta como occidentalismo $(D C E C H$, s. v. fundir), pero es bien posible que, en las Islas, sea de origen portugués, según pretende Pérez Vidal. Nótense, sin embargo, los reparos de Alvar y Llorente (I).

gago 'tartamudo'. / PV, 99; ALEICan, 524: tartamudo = gago (todas las islas); "Provincialismos"; Alvar; Guerra ; Llorente (II), págs. 194, 214 ; Lugo (gayo léase gago); Millares. // gago 'gago, gangoso, tartamudo, balbuciente'. Es bien posible que en Canarias se haya reforzado la voz castellana mediante su contraparte portuguesa idéntica, pero nada se puede comprobar. Corominas documenta gago en castellano desde 1233 ; está muy difundido en 
Hispanoamérica $(D C E C H)$. Con todo, su ausencia en Andalucia, según senala PV, arguye en favor de su posible portuguesismo en Canarias.

gaguear 'tartamudear'. / PV, 99; Alvar; Guerra (s. v. ganguear); Lugo. // gaguejar 'gaguear, tartamudear'; gall. gaguexar 'tartamudear'. En Canarias, puede ser de origen portugués, pero, en concreto, nada nos demuestra que la voz canaria (e isleña) no sea de procedencia castellana.

gallo 'chichón' ("a lump"). / gallo 'chichón' (PV, 127); “Analogia”, págs. 78-79; "Comportamiento”, pág. 246; Alvar; Guerra. // galo 'chichón'; 'a lump on the head' (Taylor). Véase PV para algunas expresiones populares, tanto canarias como portuguesas, en que se mantiene la asociación de gallo 'chichón' con gallo 'ave doméstica'.

granel (bruli) 'techo (de un cuarto)'; 'ceiling' ("Word List"); se desconoce en isleño, donde se dice troja, tanto para indicar el techo de una habitación, como para el granero (que, por otra parte, apenas se conoce) ( $D C E C H$, s. v. troj). / granel 'desván, sobrado, que, en las casas de campo, suele servir de granero y despensa; granero, cualquiera que sea su situación' (PV, 135-136, 212). Abunda Granel (y derivados) en la toponimia canaria (PV, 314; “Toponimia”, págs. 265-266). // granel 'granero'; 'celeiro, tulha' (Figueiredo); gall. 'lugar donde se recoge el trigo'. Bien puede ser portuguesismo en Canarias, pero nada quita que no sea meramente castellano, de origen náutico (DCECH, s. v. grano).

guincho 'gavilán pescador' ("fish hawk; osprey"); en Luisiana se trata de Pandion haliaetus (Peterson, pág. 70). / guincho (PV, 178); ALEICan, lám. 333. Se trata de una especie de gaviota (Larus cinereus); nótense también PV, 107 (guinchar 'gritar'); 275 (guinchos 'apero para pescar morenas'); Viera. // guincho 'gaviota; grito agudo, chirrido'; también 'gavião ferreiro ou pedreiro'; otras muchas aves incluyendo a 'águia-pesqueira' (Morais); gall. guincho 'gancho, pico' (Otero). Claro que guincho también se da en Cuba como designación de varias aves de presa, entre ellas el gavilán pescador (Santamaría). Véase $D C E C H$, s. v. gancho. Parece probable que en Canarias sea de origen portugués.

jeito 'habilidad; destreza'; jaito 'skill' (M); bruli jaito ("Word List"). / jeito 'maña, habilidad' (PV, 115); “Comportamiento”, pág. 237; Lugo; geito (Guerra; Millares); compárese también jeito 'contorsión violenta' (PV, 128). // jeito 'manera, modo; habilidad; aptitud'; 'disposição, propensão, aptidão' (Figueiredo); gall. xeito 'modo, habilidad, maña' (también Porto Dapena, págs. 81, 217); jeito 'forma o manera apropiada' (sin jeito nin dreito) (Otero); ast. xeito 'sitio, postura, colocación' (Acevedo; Rz.-Castellano, Contrib., pág. 480 ; Aspectos, pág. 125); leon. šeito 'modo, manera' (Casado Lobato, pág. 42); šeitu 'aspecto' (Alvarez, Babia).

jeitoso 'hábil, experto, diestro'; véase también ajeita'o (supra). / jeitoso 
'bien amañado, habilidoso' (PV, 116). // jeitoso 'que tem jeito para alguma coisa ; apto, hábil, habilidoso' (Morais; Figueiredo); gall. xeitoso; ast. xeitoso 'mañoso' (Acevedo).

jurgabollos 'dedo del corazón'. Igual que en Lz, 1, al perderse el significado del port. furar 'horadar', la forma isleña modifica el primer elemento - por etimología popular - a base de hurgar. / jurabollos 'dedo indice' (PV, 96); ALEICan, 501, n.: jurgaboyo (Lz, 1); “Comportamiento", pág. 241; Alvar, "Dialectología", pág. 28. // furabolo(s) 'dedo indicador' (Morais; Figueiredo); también furabolhos; trasm. fura-bolos, fura-bolhos (Moura Santos, pág. 331); gall. furabolos 'dedo indice'; ast. furabolos, furabollos (Acevedo). Véase matapiojos (infra).

legumio 'verdura' ("vegetables, like lettuce, artichoke, el cardo -that's wild artichoke- thistle"); bruli legume 'vegetable' ("Word List"). I ALEICan, 88: leguminosa $=$ legume $(n)$ (en todas las islas, menos Gs, legume domina, al competir esporádicamente con legumbre); enlegumar 'sembrar las legumbres para enterrarlas en verde como abono' (PV, 205); “Comportamiento”, pág. 229; Alvar; García Mouton; Guerra; Llorente (I), págs. 14-15. // legume 'legumbre, hortaliza'; gall. igual. En el caso de Luisiana, se podría pensar - como hace MacCurdy en el caso de la voz bruli- en un préstamo del cadjin légume (Daigle). Se explicaria así, quizás, la forma isleña como un intento de naturalizar al español la forma francesa. Es posible; pero dado el portuguesismo tan fuertemente establecido en Canarias y tratándose de un concepto tan fundamental, me parece menos convincente que sea un galicismo.

liña 'cuerda'; 'fishing line, string' (M); liña mano; liña caña ("pole line"): Así describe el anciano Martín Alfonso (de Delacroix Island) los diversos trabajos de su vida: "Yo casé caimanes, pa buŝcarme la vía, casé patoŝ, peŝqué chinchorro, peŝqué el traŝmayo, trolié, peŝqué jaibaŝ, |eh! trampiando, trabajo duro, eché la liña, muchoŝ añoŝ" $(S T, 166)$; igual en bruli : liña 'fishing line, string' ("Word List"). / liña 'cuerda delgada, cordel, bramante' (PV, 276-277); ALEICan, 699: bramante ('cuerda para hacer bailar el trompo') $=$ liña (en todas las islas) ; 849: liña de mano $=$ liña (en todas las islas, menos Fv); "Marineras"; Alvar; Guerra; Lugo; Millares. // linha 'hilo de lino; cualquier hilo; hilo de pesca'; gall. liña 'habra; hilo para coser; cordel'; ast. liña 'cuerda para pescar, envolver la peonza, etc.' (Acevedo); leon. liña 'Faden auf dem die Kuglen usw. aufgereiht werden' (Krüger, Gegenstand., pág. 273); Argentina liña 'cuerda o hilo de anzuelo' (Santamaría, Morínigo). Es muy posible que en Canarias sea sólo (o en parte) un arcaísmo, como parece implicar Corominas (DCECH, s. v. linea) o bien un vulgarismo, como en muchas partes del mundo hispánico, pero la fuerza de los demás portuguesismos sugiere a lo menos la posibilidad de una 
intervención portuguesa en el destino de la voz canaria. Como afirma Pérez Vidal, "la gran vitalidad de liña en Canarias se debe principalmente a la gravitación del mundo marinero" (PV, 277).

matapiojo(s) 'pulgar'; a veces 'dedo indice'; bruli : matapiojo 'dedo indice'; 'index finger' ("Word List"). / PV, 96; ALEICan, 501: pulgar = matapiojo(s) ; LP, 10; Go, 40; Hi, 4, 5; GC, 12; GC, 4 (matapulga); también "Comportamiento", pág. 246; "Fenómenos", págs. 70-71; Alvarez Nazario, pág. 253 y n. 9. // mata-piolho(s) 'dedo polegar' (Morais); gall. matapiollo (García, Léxico); trasm. mata-piolhos, escachapiolhos, etc. (Moura Santos, pág. 331); ast. mata-pioyos, matapjóĉus (Vigón, Rz.-Castellano, Contrib.). Como observa Pérez Vidal, matapiojos, igual que jurabollos, suele nombrarse como parte de una enumeración infantil de los dedos y sus apodos tradicionales, que en Canarias resulta ser una traducción de portugués ( $\mathrm{PV}$, $360-362$ ). Las voces usadas en las variantes canarias del recuento son indudablemente más cercanas a las de las versiones portuguesas. Ahora, en diversas formas $-\mathrm{e}$ incluyendo la correspondencia pulgar $=$ matapiojos - la carretilla es de vasta difusión. Conozco, p. ej., versiones del Brasil (Verissimo de Melo, pág. 44 : cata-piolhos) y Méjico (Garfias, pág. 84: matapiojos). Para textos canarios, portugueses y gallegos, véanse Pérez Vidal, "Folklore infantil” (1945), págs. 353-354 ; idem, Folclore infantil (1986), págs. 85-88; Coelho, pág. 13; Fernández Costas, págs. 655-656. Véase también ALEICan, $501, \mathrm{n} .(\mathrm{Lz}, 1) ;$ y jurgabollos (supra). El portuguesismo canario, meringuiño 'dedo meñique' (PV, 97), se desconoce en Luisiana, donde en isleño se dice el margarito 'little finger' (M); ALEICan, 501: meñique $=$ meringuiño (y variantes) (LP); pero margaro y margarito son las voces predominantes y mucho más difundidas (Go, Hi, Tf, GC, Fv, Lz, Gs). En el dialecto bruli, la margarita es el dedo del corazón ('third [long] finger' ["Word List"]). Véase también "Analogía", págs. 70-72; Alvar; ídem, "Dialectología", págs. 27-28.

melorico: voz sin significado con que comienzan unos versitos infantiles. Entre los isleños, acompañan al juego del escondite: "Pico, pico, melorico, / sab'andar, sabe a correr / y sabe irse a esconder, / atrá de la casa del señor rey" (ST, 106-107). / malorico, melorico, meldorico, menorico: Se dan en una cantinela infantil esencialmente idéntica: "Pico, pico, melorico, / quien te dio tamaño pico" (M. R. Alonso, pág. 31 ; PV, 121-122, 359-360); también "Analogía”, págs. 68-70. // Pérez Vidal explica la voz canaria - ya desprovista del significado- mediante versiones portuguesas y gallegas que comienzan: "Sorrobico, massarico, / quem te deu tamanho bico?" (Braga, Cantos, pág. 180); “¿Pico, pico, mazarico, / quén te deu tamaño bico?” (Fernández Costas, pág. 666). Resulta que tales versiones galaico-portuguesas son las únicas que hacen sentido, pues, en portugués, maçarico designa una 
variedad de aves notablemente picudas (Taylor), mientras que, en gallego, mazarico es el alción o martín pescador. Para versiones canarias, véase el artículo de Pérez Vidal, AEA (1962); también "Folklore infantil" (1945), págs. 363-367 ; Folclore infantil (1986), págs. 100-117; Cuscoy, pág. 122. La forma melorico (y afines) se conoce en otras áreas además de Canarias. Así, en Colombia, se dan unos versos que tienen que ser de origen canario: "Pico, pico, melorico, / ¿quién te dio tan largo pico?” (Arias, pág. 118). Las variantes puertorriqueñas, con la voz mandorico, sugieren quizás un nexo directo con lecciones gallegas (o portuguesas), más bien que con las canarias: "Pico, mandorico, / ¿quién te dio tamaño pico?..." (Cadilla de Martínez, págs. 104-108); "Pico, pico, cantorico, / ¿ quién te dio tremendo pico? / La seca, la meca, la tortoleta" (versión inéd. que debo a la generosidad de mi colega, Aida La Caro, nacida en Río Piedras).

mico: haser el mico 'hacer pucheros' (hasiendo el mico: "getting ready to cry"); está miqueando. / bico 'puchero, gesto o movimiento que precede al llanto verdadero': hacer el bico o hacer bicos (PV, 120); "Arcaísmos", pág. 37; Guerra; Millares; Navarro. // bico 'pico (de las aves); boca (del hombre)'; gall. bico 'beso; pico (de las aves); hocico'. Véanse PV, 141; $D C E C H$, s. v. pico. En la expresión isleña, se ha realizado un cruce del canario-portugués bico con alguna de las varias acepciones castellanas de mico - cruce, por otra parte, facilísimo desde un punto de vista fonológico.

millero: igual que el chaque 'redwinged blackbird' (Agelaius phoeniceus); véase Peterson, págs. 225, 230 ; chaque $=$ fr. cadjin choc 'blackbird'; choc aile rouge 'redwinged blackbird' (Read, pág. 26). / millero 'pinzón' (PV, 179); Alvar; Viera. // milheiro 'pintarrojo'; millero también se da en Andalucía (Whinnom, núm. 527; Alcalá Venceslada: 'pinzón real' y otros).

millo 'maíz (molido)'; también bruli : millo 'corn' ("Word List"). Para los isleños, el maiz sin moler es mái o maí. / PV, 213; ALEICan, 1015: maiz $=$ millo (se da en todas las islas; sólo en dos puntos de $\mathrm{Hi}$ alterna con maiz); nótese también 225: calabaza comestible = calabaza de millo (sólo GC); "Provincialismos"; Alvar; García Mouton; Guerra; Lugo; Viera (s. v. maíz). // milho; gall. millo; miyo (Taboada, pág. 62 ; véase también Otero, s. v. millo das paredes); ast. miyo 'mijo' (Sánchez Vicente; Acevedo; Vigón); leon. miyo 'maíz' (Baz, pág. 93); salam. trigo millo 'maíz' (Lamano); muy difundido en América en varias acepciones: Chile, Puerto Rico; en México y Centroamérica 'maíz' (Santamaría; id., Mejicanismos; Alvarez Nazario, págs. 112 [millito], 154). Nótese $D C E C H$, s. v. mijo.

morianga 'fresa'; 'strawberry' $(\mathrm{M})$; pero bruli freza (con -s- sonora; correspondiendo a un préstamo relativamente reciente del fr. cadjin fraise). / moriangano, moriángana, moranga, morango (PV, 200-201); "Comportamiento", pág. 233; Alvar ('zarzamora'); Lugo; Viera (s. v. fresa). // mo- 
rango 'fresa silvestre'; morangueiro (planta); gall. 'fresa; fruta semejante a la zarzamora, pero de color encarnado'. Véase $D C E C H$, s. v. fresa.

murchar(se) 'marchitar': "se murcha, se murchó, 'tá murchando"; también se dice marchar (= murchar + marchar + marchitar). / murchar 'marchitar' (PV, 206). // murchar; gall. muchar, murchar (también Taboada, pág. 29). En el j.-esp. oriental, consta el portuguesismo amurchar(se) 'marchitar' (Wagner, Beiträge, 136; Luria, $\$$ 165, 170; Sala, pág. 59).

patuñero 'fango, lodo (líquido)' ('it's just a mess, everything is just slush"). Se refiere a las condiciones que tienen que soportar el jaibero y el pescador de chinchorro o trasmallo. Como dice una décima: "Un jaibero por la costa, / con el agua a lą rodiyą, / con el salabrito al hombro, / no hay carro que lo siga" (ST, pág. 33; también págs. 158, 166). / patuñero 'lodazal'; patuñar 'marchar con los pies desnudos en terreno fangoso o moldear con los pies el barro, preparándolo para la obra de albañilería' (PV, 300); “Comportamiento”, pág. 232. // patinheiro 'holladero, camino o lugar enfangado, donde quedan las huellas de los pies de los que por alli pasan'; patinhar 'chapotear'; 'to slosh, dabble (in water); to play, splash about (in water)' (Taylor).

peta 'joroba'; mi informante, Irvan Pérez, recuerda haber oído la palabra a ancianos, pero ya no se usa. / PV, 99; ALEICan, 408: joroba del dromedario $=$ peta $($ sólo en $\mathrm{Tf}) ; 522:$ jorobado $=$ petudo (se da en todas las islas, menos GC); Alvar ; Llorente (II), págs. 194, 214, n. 10; Lugo; Millares. // Pérez Vidal sugiere la etimología: "el port. peta es, en algunas herramientas agrícolas, una pequeña lámina, afilada o no, que sobresale a la espalda del corte principal o pecho" (PV, 99-100; donde se da amplia documentación); también "Comportamiento", pág. 236. Compárese gall. peta 'prominencia posterior de las azadas' (Taboada, pág. 24).

peto 'pájaro carpintero' ("eŝ como el pájaro carpintero, pero máŝ pequeño, ... small variety"); bruli peto 'woodpecker' ("Word List"). Para los numerosos woodpeckers (Picidae) conocidos en Luisiana, véase Peterson, págs. 146-151. Supongo que el peto ha de corresponder a los menores, como, p. ej., el hairy (Dendrocopos villosus) o el downy (D. pubescens). / peto (PV, 179); ALEICan, 312: pájaro carpintero = peto $(\mathrm{Tf}, 5,30 ; \mathrm{GC}, 12)$; Alvar; Viera. Contrástese peto con cast. pito. // peto 'nombre vulgar extensivo a algunas aves trepadoras'; 'pássaro trepador, pica-pau' (Figueiredo); gall. peto 'pico; ave trepadora'; ast. peto 'pico (pájara) o picamaderos' (Acevedo; Whinnom, pág. 128).

picar 'guiñar' : picando el ojo ("winking"). / picar el ojo 'guiñar el ojo' (PV, 108); ALEICan, 479: guiñar = picar (en todas las islas; en tres puntos de Go y Hi: repicar; LP, 10, 30: picar de ojo); Guerra. // piscar 'guiñar, cerrar un ojo, con disimulo, para dar señal de algo'. Guerra documenta 
picar con el mismo sentido en Venezuela, donde, según parece razonable suponer, ha de ser un canarismo. La desaparición de la $s$ de piscar se ha de relacionar con la articulación aspirada y luego la pérdida de la $s$ ante otra consonante en Canarias, que facilitaría la asociación con cast. picar.

pilla 'pila; montón'; 'pile, heap' (M): “Queve'o tenía una pilla de animales"; "Y teniane ... pillą, pillą 'e varva" $(S T, 145,149)$; empillar 'amontonar' ("pile up"); bruli pilla 'pile, heap' (“Word List”). / pilla (PV, 254, 279-280); empillar 'apilar' (PV, 251-252); "Comportamiento", pág. 247; Lugo; Millares (s. v. salado). // pilha; $D C E C H$, s. v. pila.

quejo 'quijada ; mandibula inferior; barbilla' ("chin”); 'jaw' (M); pero en bruli se dice quejá 'jaw' ("Word List"). / PV, 97; Guerra; Millares. // queixo 'mentón; barbilla; quijada inferior'; trasm. queixo [kaǰsu] (Moura Santos, pág. 339): gall. queixo 'barbilla'; leon. queixiellos 'mandibulas' (Garrote); extremeño quejos (PV, 97); queho 'la soga con que se ata la mandíbula de un animal' (Viudas Camarasa); $D C E C H$, s. v. quijada.

rañoso 'sucio' ("hasn't taken a bath"); pero también se dice roñoso; bruli rañoso 'dirty'; rañosar 'to make dirty, to get dirty' ("Word List"). / rañoso (PV, 108); raño (< port. ranho 'moco') (PV, 123); Alvar; Guerra. // ranhoso 'mocoso; rahez, vil, despreciable'; gall. rañoso 'tramposo en el juego, mezquino, avaro'. Véase $D C E C H$, s. v. roña.

rente 'corto, a rape, cerca'; cortar a rente "cutting as close as you can; flush"; 'short, close' (M); en bruli igual ("Word List"). / cortar rente 'corto, junto a la raiz; al rape; a ras' (Lugo). // rente 'próximo, inmediato, contiguo'; gall. 'junto, pegado, inmediatamente, cerca'; 'al lado, junto a' (Porto Dapena, pág. 207); 'ras' (Otero, pág. 65). Véase también $D C E C H$, s. v. randa.

safra 'época, estación'; zafra 'season' (M) ; en una décima: "Y esta $z a-$ fra que viene / verán lo que va a pasar" (MacCurdy, “Los «isleños»”, pág. 111). Según observa MacCurdy: "Zafra is used to designate any season, such as fishing season, trapping season, etc." (M, 87). Tradicionalmente había entre los isleños cuatro zafras principales: la safra la trampa (del 15 de nov. al 15 de marzo), en la que se trampeaba las ratas de agua y otros animales; la safra la jaiba (del 15 de marzo hasta mayo), para la pesca del cangrejo (de agua salada); la safra el peje o la liña (mayo, junio, julio), y la safra el camarón (agosto hasta el 15 de nov.) / zafra 'todo proceso de la cosecha y molienda de la caña de azúcar' (PV, 235); zafrar 'acabar una cosa' (Alvar). // safra 'cosecha abundante'; 'colheita' (Morais); 'colheita, boa nascença de frutos' (Figueiredo); 'harvest, crop, harvest time' (Taylor). En catellano, zafra está tomado de portugués y documentado sólo desde $1836(D C E C H)$, pero en las Islas lo documenta Pérez Vidal ya desde 1507: "En Canarias es portuguesismo" (PV, 235).

San Juan: (mes de) San Juan, el San Juan 'junio'. / ALEICan, 727 : 
junio = San Juan, mes de San Juan (en todas las islas alterna con junio). // mês de São João; gall. San Xoan (D. Alonso, “Junio y julio”, pág. 394, n. 15, 405-406; en un versillo gall.: "polo San Juan, sécall'a primeira raíz o pan” [págs. 393-394]); en un romance asturiano: “ ¿Pa qué meten tanta leña, / siendo el mes de San Juan?” (Munthe, núm. 3.85-86). En judeoespañol, tanto en Marruecos como en Oriente, se dan casos fosilizados en versos de romances: "En el mes de Sanğiguale, / cuando las ovežas paren" (Salónica; Attias, núm. 55) ; "Por vida tuya, Espinel, / ¿ cuándo era tu nacida? // Si nacistes en San Juan / o en la Pascua Florida?" (Catalán, "Romancero medieval”, pág. 478). También se da en murciano y en andaluz (A1var). Con todo, creo que la designación es primordialmente de carácter occidental y que la expresión canaria bien puede contar como un posible -0 probable- origen portugués. En Canarias, julio es el (mes de) Santiago y noviembre corresponde a San Andrés. Véase ALEICan, 729 (general) y 737 (Hi, 1, 2, 10; Tf, 21). En isleño también se decía antiguamente el mes de Santiago 'julio'.

sarampio 'varicela' (“chicken pox"); 'measles' (M); en bruli: 'measles' ("Word List"). / sarampio 'sarampión' (PV, 130); ALEICan, 530 : sarampión = sarampio (de uso general, alternando en algunos puntos con sarampión). // sarampo 'sarampión'; gall. sarampo, sarampelo.

sato 'mapache' (Procyon lotor); 'raccoon' (M). En la isla de San Bernardo se dice: "Más cobarde que un sato", por la costumbre que tiene el pobre animalejo de taparse la cara con las patas cuando lo van matar. En isleño también se dice raposo. No existe sato entre los brulis; al mapache le decían marsué o šawí (voces de origen cadjin) ("Word List"); para el animal : Burt y Grossenheide, págs. 54-55, 100. / ALEICan, 412: cachorro = sato, satito ; sólo se da en dos puntos: $\mathrm{Hi}, 2$ y 10 , alternando con perrito. // gall. xato 'ternero pequeño'; ast. xato, xatu, šjátu 'jato, ternero' (Acevedo; Canellada ; Cano González; Conde Saiz; Rz.-Castellano, Aspectos, pág. 127; Sánchez Vicente; Vigón); leon. šato '[ternero] hasta el año' (Casado Lobato, pág. 162); xato 'ternero' (Garrote; Alvarez, Babia). Claro que jato ya consta en el $D R A E$ ('ternero o becerro'); en cast. está tomado del gall. o del ast. (DCECH, s. v. choto). En Cuba y Puerto Rico, sato vale como 'perro pequeño, de pelo corto, (muy) ladrador (y andariego)' (Santamaría ; Malaret); en Colombia, se aplica al 'ganado de pequeña estatura' y a 'las aves pequeñas' (Di Filippo). Convence, a mi ver, lo que dice Buesa Oliver, al relacionar el sato herreño con gall. y ast. jato, xatu: "Se trata, pues, de un occidentalismo que hay que añadir a los numerosos que existen en el léxico canario. ... Semánticamente, el rasgo 'cría' de un animal - la vaca - se ha desplazado a otro, la perra" (pág. 235). No hay que decir que el desarrollo fonológico es intachable. De 'perrito', el paso a 'mapache', en el dialecto isleño, sería faci- 
lísimo, debido al aspecto marcadamente canino del animal y su tamaño relativamente menor en comparación con el perro (aunque es capaz de alcanzar un peso de unas 35 libras [13 kgs.]). La correlación semántica 'cachorro' = 'becerro' se da también en un regionalismo angloamericano del oeste de los Estados Unidos, donde la voz dogie designa al 'becerro huérfano o redrojo' ('a young often runty calf, usu[ally] one that has no mother' [DARE]; 'a motherless calf' [Mathews]), que quizás tenga su origen en doggie 'perrito'; con todo, la etimología no es segura (dogie se pronuncia con o, mientras doggie tiene Q).

secura: tener secura en la boca 'tener la boca seca'. / secura 'sed' (PV, 109). // secura 'sequedad'; pop. 'sed'; gall. y bable igual en forma y significado; en bable: tengo muita secura (Rz.-Castellano, Contrib., pág. 146).

solla'o 'tablado' ('frame'); bruli sollado 'suelo (de una casa)'; 'floor' ("Word List). Véase también ensolla'o (supra). / sollado 'cualquier pavimento doméstico que no sea de tabla'; solla'o 'suelo de madera'; suallado 'piso de madera entarimado'; sollar 'poner suelo'; suallar 'entarimar, entablar el suelo' (PV, 138); “Comportamiento", págs. 234-235, 245; Alvar. // soalhado 'entablado, entarimado; tablas para el suelo; el suelo'; 'madeiramento para soalhar'; soalho 'pavimento de madeira' (Morais); gall. soallo 'piso, entarimado, entablado del suelo'.

tamborin: aplícase a varios peces de la familia de las Sciaenidae ("drum fish"), seguramente bajo la influencia del inglés. Para las especies corrientes en el norte del Golfo de Méjico, véase Walls, núms. 306, 312-315. / tamborín, tamboril 'pez muy conocido y popular; el Tetradon honckenii Block'; peje tamboril o tambori (PV, 287); Guerra. En Canarias, por lo tanto, se trata de un pez completamente diferente, de la familia de las Tetradontidae y de las Diodontidae ( $p$ uffer fish en inglés), de los que hay también varias especies en el Golfo (Walls, núms. 491-499). // tamboril 'rape, pejesapo, pez marino acantopterigio'; peixe tamboril (PV, 287); para gall. tambor, véase $\mathrm{Ríos} \mathrm{Pa}$ nisse, I, 305, 392; tamborin y tamboril también existen en cast., pero al parecer, sin aplicarse a peces $(D C E C H$, s. v. tambor).

tapume, tapum 'techo' ("roof"); 'vigas' ("rafters; the frame for the roof"); tapún 'roof' (M). / tapume, tapumen 'trama de la tela' (PV, 255); ALEICan, lám. 648: trama = tapume (LP, Hi). // tapume 'cerca, cercado; tabique, vallado; barrera'; también: 'qualquer coisa que tapa' (Morais); 'vedação de un terreno, feita com tábuas; sebe; o mesmo que valado' (Figueiredo); gall. 'urdimbre'; más datos: PV, 255. Nótese la diferencia semántica entre las formas canarias y las isleñas, en cuanto éstas quedan más cercanas a la voz portuguesa.

taramela 'pestillo (de madera)' (tiene un agujero en el medio) ("latch, of wood, with a hole in the middle"). / taramela 'tarabilla; zoquetillo de ma- 
dera que sirve para cerrar puertas y ventanas; tabla con un agujero central por el que se introduce y sujeta el extremo superior de la manija o palo del molino de mano; fig. 'lengua'; tramela 'agujero para echar el grano en el molino' (PV, 98, 138, 259-260; ALEICan, 548: taravilla = taramela $(\mathrm{Go}$, Tf, GC, Fv, Lz, Gs); Alvar; García Mouton; Guerra ('pedazo de madera giratorio que se disponía tras las puertas y ventanas para cerrarlas'); Llorente (I), pág. 20 ; Llorente (II), págs. 194, 214, n. 14; Lugo ; Millares. // taramela, tramela 'zoquetilla de madera giratoria que cierra las puertas o ventanas; tarabilla'; fig. 'lengua; mujer parlanchina'; se dan otras diversas manifestaciones semánticas en contextos dialectales: p. ej., L. de Vasconcellos, Estudos, pág. 90; Lopes Alves, Ericeira, pág. 234; Krüger, Gegenstand., págs. 129-130.

tarsuelo 'orzuelo'. / tarsuelo (y variantes: torӨuelo, transuelo, etc.) se da en todas las islas, junto - esporádicamente- con otras formaciones popularetimológicas propias más bien del castellano (ansuelo, sarsuelo) y, a veces, con la forma estándar orsuelo (ALEICan, 518: orzuelo); Alvar (arzuelo, onzuelo, tarzuelo); García Mouton; Llorente (II), págs. 195, 219-220, n. 43. // terçol, terçolho; es de esta segunda forma - más popular- que tal vez provenga la voz canaria, adaptado el sufijo al castellano. Nótense Lopes Alves, Ericeira, pág. 233 (terçolho); gall. tirizol; también tirizó, tirizoilo y otras formas (Porto Dapena, pág. 75, n. 72; Quibén, págs. 287-288).

templero 'ingrediente que se añade a la comida (p. ej., el caldo) para enriquecer el sabor' ("my grandma used that, a little extra piece of meat, to bring out the flavor"). / templero 'trozo de algún cuerpo o grasa, variable según las versiones, que ciertas cocineras introducen un momento en el caldo, hallándose éste cociendo, para condimentarlo y darle fuerza, y que después guardan para sucesivas ocasiones' ("Analogía", pág. 82). // tempero 'condimento, aderezo, sazonamiento'. Como observa Pérez Vidal, “templero parece resultado de un cruce del port. tempero 'substância com que se aduba a comida' y el cast. templar" ("Analogía"). Véase Morais.

titi 'tio'; 'uncle' (M); tita 'tía'. En la aldea de Reggio (Bencheque), existía, hasta hace poco, una abacería (isleño cabarete) designada con el letrero "Teta's Place" (con ortografía anglo-sajona). / titi 'tío o tía' (Lugo). // titi 'tío o tía (en lenguaje infantil)'; también titio, titía ; andaluz titi 'tía (expresión cariñosa dada por los niños)' (Alcalá Venceslada); Puerto Rico : tití 'tía' (Alvarez Nazario, pág. 213). Todas las voces del lenguaje infantil ofrecen -obviamente- unos problemas muy especiales. Sólo la abundancia de los demás portuguesismos nos induce a pensar que en Canarias la forma quizás sea un portuguesismo o, por lo menos, que haya sido reforzada en su uso por la coincidencia con el portugués.

tolete 'persona torpe; garrote corto' ("a stick"); toletaso 'golpe con un 
palo'. / tolete 'torpe, lerdo, estúpido' (PV, 119); “Marineras”; Guerra ('palo gordo y de por lo menos un metro de largo'; 'hombre cerril, ceporro, zoquete, torpe, cretino'; toletazo 'golpe y paliza dada con el tolete); Millares. // tolete 'thole pin; a roller made of wood or other material' (Taylor); tolo 'tolondrón, aturdido, desatinado, loco'; gall. tolo 'loco, disparatado'. El desarrollo semántico es obvio (esp. ceporro, porro, zoquete; inglés blockhead, clodpole, loggerhead, stick, stock, woodenhead; también Millares, s. v. teni$q u e$ ). Es voz marinera muy conocida en diversas regiones del mundo hispánico. En Canarias podría ser un portuguesismo y, al efecto, creo que conviene tener presente la opinión de M. L. Wagner, a quien le "parece más probable el origen portugués [de] la acepción 'estúpido"” (reseña de Millares, pág. 83, n. 1). La influencia de tolo podría haber sido decisiva. Con todo, téngase en cuenta la ponderada evaluación de Llorente (I), págs. 73-74.

tontura 'vértigo' ("woozy, dizzy"); 'dizziness' (M); igual en bruli ("Word List”). / tontura 'vértigo, mareo' (PV, 130); ALEICan, 510: náuseas = tontura (GC, 10, 20); Lugo; Millares. // tontura 'vértigo, mareo, vahído; turbación del juicio'; 'perturbação de cabeça; vertigem; estonteamento' (Figueiredo).

totiso 'cogote' ("lower part of the neck"). / totizo 'cogote' (PV, 98); ALEICan, 484 : cogote $=$ totizo (todas las islas, pero alternando con corona $\mathrm{y}$, a veces, con cogote); “Comportamiento", pág. 238; Alvar; Guerra ('cuello'); Millares. // toutiço 'nuca, parte posterior de la cabeza; la cabeza; cerviz'; gall. toutizo 'el curuto [coronilla] de la cabeza'.

trangullón: comer a trangullones 'comer sin masticar' ("not to chew your food"). / trangullón: comer a trangullones 'comer atropelladamente, a grandes bocados' (PV, 109-110); Guerra (s. vv. tragullones, trangullones); Millares (s. v. trangullir). Nótese también, especialmente en La Palma: al trambullón 'atropelladamente, sin esmero ni miramiento'. // Pérez Vidal conecta la voz canaria con port. trambolhão 'caída ruidosa': trambolhar 'tumbar, rodar, hablar con embarazo'; gall. trambullón 'batacazo, golpe fuerte y estrepitoso que da una persona al caerse'.

urrar 'bramar, rugir, mugir' ("bellow like a bull"). / PV, 243-244; ALEICan, 359: mugir $=$ urrar $(\mathrm{Hi} ; \mathrm{Tf}, 2,20 ; \mathrm{Lz}, 3)$; también urriar $(\mathrm{Tf}$, 6); Alvar; García Mouton; Llorente (I), págs. 20-21; compárense urrido, urrir (PV, 244). // urrar 'rugir, bramar, berrar'; gall. igual.

vida: tiro de la vida 'cordón umbilical'. / vida 'cordón umbilical' (PV, 98, 362-363; “Analogía”, pág. 72). // vide, envide ; gall.; PV sugiere el origen: "Etimología popular del cast. vid y tal vez mejor, del gall. y port. vide, ambos de igual sentido" (98). El portuguesismo no es, por lo tanto, seguro, pero resulta muy sugerente la hipótesis. Véase $D C E C H$, s. v. vid. 
Lo primero que nos impresiona de esta lista es su brevedad ${ }^{13}$. Frente a los centenares de portuguesismos y occidentalismos reunidos por Pérez Vidal -cuento unas 900 entidades-, nuestros dialectos luisianenses no nos proporcionan más que un escueto repertorio de 82 artículos (y de éstos, algunos dependen de un solo étimo: como, p. ej., ajeita'o, jeito, jeitoso). Conviene tener en cuenta, claro está, el incalculable cambio de vida, la enorme dislocación, que supone lo que va de los emigrados canarios que llegaron a Luisiana a finales del siglo xvirr a los isleños y brulis del siglo xx. Aunque llegan a América siglos después del descubrimiento, en lo que se refiere a la novedad de sus circunstancias, la situación con la que se enfrentan los emigrantes canarios de fines de los 1700 s dista poco, en lo esencial, de la de los primeros colonizadores. Acordémonos, a este propósito, de la notable caracterización del "Mundo Nuevo" que nos ofrece Francisco López de Gómara: "También se puede llamar nuevo por ser todas sus cosas diferentísimas de las del nuestro. Los animales en general ... son de otra manera; los peces del agua, las aves del aire, los árboles, frutas, yerbas y grano de la tierra ..." (Vedia, I, 156). Se enfrentaban los emigrados con un mundo ambiente, en que toda la naturaleza —animales, aves, reptiles, peces, insectos, árboles y plantas - era completamente distinta, ajena a la que habian conocido en Canarias ${ }^{14}$. De agricultores, artesanos, gentes de mar, que participaban en una comunidad socio-económica bastante compleja y diversificada, los descendientes de aquellos colonizadores canarios han pasado, en el caso de los isleños, a practicar unos oficios muy especializados, que, aparte de la pesca, no tienen nada que ver con lo que hacian sus antepasados (véase bajo la voz safra). En

1s Huelga decir que, en lo que se refiere al supuesto portuguesismo de una serie de voces canarias - e isleñas - a menudo nos movemos sólo en el terreno de lo probable o lo posible. Téngase en cuenta, por ejemplo, las finas matizaciones etimológicas propuestas por Llorente (I), págs. 7-36. En otros casos, me he visto obligado a considerar y luego excluir de la lista ciertas voces isleñas - algunas indudables oocidentalismos, otros meros arcaismos- cuya gran difusión en territorios castellano-peninsulares y en Hispanoamérica dificulta el que en Canarias hayan sido de origen portugues o siquiera occidental: p. ej., aceda 'estropeada' (se refiere a la leche del calostro [beleten]); amolar 'afilar'; banderita 'milano'; cuadril 'hueso de la cadera'; chopa 'pececillo'; chubasco 'lluvia pasajera'; desconchabar 'desencajar'; emborcar 'capotar'; engruñado 'arrugado'; ensetar 'empezar'; escarrancharse 'espatarrarse'; fogalera 'hoguera'; fogar 'horno'; escacharse 'escaparse'; frangollo 'revoltijo, lfo'; frangollón 'chapucero'; garañón 'caballo o macho cabrío (de crfa)'; pintasilba 'jilguero'; rescaldo 'rescoldo'; rolar 'rodar'; safado 'descarado, insolente'; triguero 'chochin'; trillo 'senda, vereda'; trampicar 'tropezar' (bruli); tútano 'tuétano'.

14 Nótense, p. ej., los abundantes préstamos del francés cadjin: barbú 'bagre'; cawên 'tortuga'; congó 'culebra'; cribis 'cangrejo (de agua dulce)'; paifin 'cierta hierba (de pantano)'; pisú 'gato montés'; raybuá 'zarigüeya'; sueta 'lechuza'; surí 'ratón'; wanconú 'especie de árbol'; wawarón 'rana toro'; amén de los muchos nombres de patos y otras aves acuáticas: canargri, canar francés, canarnuar, puld6, y otros muchos. Véanse mis «Tres dialectos*, págs. 291-292, y MacCurdy, «Water-Fowlw. Una sistemática encuesta sobre la fauna de St. Bernard y la terminologfa isleña correspondiente, realizada en 1980, está aún sin transcribir. 
el siglo xix, antes de arraigarse en las tierras aluviales del sur de la parroquia de St. Bernard, los isleños si habían sido agricultores y algunos ganaron gran fama como expertos amaestradores de bueyes, pero al caer tales prácticas en desuso, otros varios portuguesismos - además de los que se habian perdido desde el principio mismo de la colonización americana- sin duda habrían desaparecido del léxico isleño. De las 26 categorías establecidas por Pérez Vidal, sólo 18 están representadas entre los isleños:

1. el cuerpo humano: barriga de la pierna, jurgabollos, matapiojo(s), quejo, totiso, vida.

2. defectos físicos: cambado, cambar, gago, gaguear, peta.

3. acciones y cualidades físicas: picar, rañoso, secura, trangullón.

4. acciones y cualidades psiquicas: ajeita'o, bobanco, cabucar, devaso, jeito, tolete.

5. los nin̄os: adivina, melorico, mico, tití.

6. enfermedades / accidentes: arrumbado, engasgarse, gallo, sarampio, tarsuelo, tontura.

7. la casa: ensolla'o, fecha, fechadura, fechar, fechillo, rente, solla'o, tapume, taramela.

8. el hogar: emborrayar, escaniyo, fonil.

9. comida / vestido: alfinel, fondaje, templero.

10. tiempo atmosférico: arco la vieja, chovisnear, chumbo, enchumbarse.

12. animales: andoriña, bicho, corujo, guincho, millero, peto, sato, tamborin.

13. árboles: enciña.

14. aperos: fecha.

15. hortalizas / frutales: bichento, legumio, morianga, murchar.

16. trigo / maiz: empayar, empayorar, millo.

19. animales domésticos: urrar.

25. el mar: chumasero, empate, engoyar, liña.

26. varios: empillar, ferrugiento, ferruje, pilla, San Juan.

Notemos, en primer lugar, que algunas categorías $(13,14,19)$, en lo efectivo, apenas son significativas, en cuanto las representa una sola palabra en cada caso. $\mathrm{Y}$ echamos de menos realidades enteras y de importancia crucial en la vida tradicional canaria. Según los apartados de Pérez Vidal, faltan: los terrenos (11), las viñas (17), la caña de axúcar (18), la cestería (20), los tejidos (21), los molinos (22), otros varios oficios (23) y los transportes (24). Huelga explicar semejantes claros: representan actividades en las que ya no intervienen los isleños para nada.

El profundo reajuste que supone la emigración a tierras americanas que- 
da reflejado también en nuevos contenidos semánticos: Así castrar (la piel) pasa de significar en el español canario 'irritar por el calor o el frio' a designar en Luisiana el proceso especial de 'curar con sal' las pieles de las ratas de agua. En Canarias, chumbo se refiere a una 'llovizna persistente con niebla', mientras que, en Luisiana, aludiendo a la condición de estar mojado, pasa a significar figurativamente 'estar borracho'. Empayar y empayorar, aunque no los encuentro documentados en Canarias, obviamente se referían originalmente a la paja (port. palha) — como aún reconoce mi informante-pero ahora aluden a la cosecha y preparación de la varva (Spanish moss), puesto que en la parroquia de San Bernardo no hay tal cosa como la cosecha de mieses. Patiñero en Canarias alude a un lodazal cualquiera, mientras que, en Luisiana, bajo la forma patuñero, se refiere específicamente al fondo fangoso que encuentra el pescador o el jaibero. al tener que caminar por el agua. De significar 'cachorro, perrito' en Canarias, sato pasa a designar - por su aspecto perruno- a un animal desconocido en Europa, el mapache. En Canarias, la zafra comprende todo lo que tiene que ver con la cosecha y la molienda de la caña de azúcar, pero en Luisiana se aplica a cualquiera de las muy variadas actividades que ocupan el ciclo anual isleño: la safra la trampa, ... la jaiba, ... el peje y ... el camarón.

Los brulis, por su parte, han seguido siendo pequeños agricultores casi hasta la actualidad, pero, aquí también, otros factores de la nueva ambientación americana habrán ocasionado pérdidas léxicas masivas. Nuestro conocimiento imperfecto y fragmentario de aquel dialecto ya extinguido impide que conozcamos los detalles de aquel proceso. Los datos brulis son muy pobres: Sólo en 20 casos (entre nuestros 82) comparten isleños y brulis un mismo portuguesismo: alfinel o finel / finel; bicho pelú; cambar; emborrallar; fechadura; ferrugiento / ferroyento; ferruje; fondaje; jeito / jaito; legumio / legume; liña; matapiojo(s); millo; peto; pilla; rañoso; rente; sarampio; solla'o, tontura. Hay un solo caso en que el bruli nos documenta un portuguesismo desconocido entre los isleños: granel 'techo (de un cuarto)' -reflejo, sin duda, del carácter agrícola de las ocupaciones brulis. Aunque poco o nada se puede hacer con tan exiguos datos, veamos de paso las categorías representadas por los pobrísimos restos brulis:

1. el cuerpo humano: matapiojo.

2. defectos físicos: cambar.

3. acciones y cualidades físicas: rañoso.

4. acciones y cualidades psíquicas: jaito.

6. enfermedades / accidentes: sarampio, tontura.

7. la casa: fechadura, granel, rente, sollado.

8. el hogar: emborrallar. 
9. comida / vestido: finel, fondaje.

12. animales: bicho pelú, peto.

15. hortalizas / frutales: legume.

16. trigo / maiz: millo.

25. el mar: liña, pilla.

26. varios: ferroyento, ferruje.

Entre los brulis no consta ninguna categoría canaria adicional no representada entre los isleños. O sea, faltan las mismas: terrenos (11), viñas (17), caña de azúcar (18), cestería (20), tejidos (21), molinos (22), otros varios oficios (23) y transportes (24); y otras cuatro además : niños (5), atmosférico (10), árboles (13), aperos (14) y animales domésticos (19) (estas tres últimas ya representadas entre los isleños por una sola palabra en cada caso). No nos puede extrañar la ausencia de viñas, cestería, tejidos y molinos, pero, dados los oficios practicados por los brulis - a diferencia de los isleños- sí nos podría sorprender la falta de voces alusivas a los terrenos, los aperos y los transportes, así como también especialmente a la caña ${ }^{15}$. Podríamos tal vez intuir en esta pobre lista la comunidad de las masivas pérdidas léxicas entre los emigrados canarios, sean los que fueran los oficios a que luego se iban a dedicar, una vez establecidos en el Nuevo Mundo - tras rigurosos sufrimientos y desastres ${ }^{16}$. Lo que sí sale muy a las claras de nuestro repertorio de lusismos isleño-brulis es su carácter eminentemente canario. Poquísimos son los casos en que no encontramos correspondencias -léxicas y semánticas- muy exactas entre las voces recogidas en Luisiana y sus congéneres canarios. Sólo en cuatro casos - chumacero, empayar, empayorar, enciña - no encuentro documentación canaria. En lo que se refiere a chumacero 'mazo de calafatear', en comparación con la voz canaria y castellana chumacera 'pieza de madera en la que se inserta el tolete', el contenido semántico es tan diferente $-\mathrm{y}$ más cercano a las implicaciones originarias de chuma̧̧o- que nos insta, en un principio, a pensar en un posible portuguesismo autóctono. Pero estoy convencido de que, en estos cuatro casos también, nos las tenemos sencillamente con unos portuguesismos canarios que faltan en la documentación a mi alcance. De haberse producido alguna hipotética influencia lingüística de unos supuestos inmigrantes portugueses radicados entre los isleños, es de pensar que las condiciones, tan radicalmente diferentes de las que existían en Canarias, habrían dado lugar a la adquisición de unos portu-

15 Hubiera sido interesante explorar el cultivo de la caña de azúcar entre los brulis en comparación con el rico léxico canario de origen portugués analizado por Pérez Vidal (PV, 223-237). Para los brulis y la producción azucarera, véase el libro de Din, págs. 166-167.

16 Sobre las enormes dificultades experimentadas por los antepasados de isleños y brulis durante los primeros años de la colonización, véase Din (págs. 28-63); también Acosta Rodríguez (págs. 142, 155, 158). 
guesismos de carácter muy distinto de los que podemos rastrear entre los isleños.

Si echamos un vistazo a otra área castellano-hablante donde también se ha producido una notable influencia portuguesa, nos encontramos - dadas unas circunstancias diferentes de las de Canarias- con un repertorio de préstamos bastante distinto del que se documenta en las Islas. Me refiero a los portuguesismos del andaluz occidental, sobre todo de la provincia de Huelva. En un repertorio de unos 60 préstamos, pocos son los casos en que el inventario de lusismos andaluces coincide con el de Canarias. Sólo doy con los siguientes -14 en total : abanador 'soplillo'; abanar 'soplar'; alpende 'cobertizo, pesebre'; borralla 'ascuas'; cañete 'zurdo'; cardume 'banco de pescado'; coruja 'lechuza'; fañoso 'gangoso'; fechar 'cerrar'; fogaje 'sarpullido'; gallo 'gajo'; payo 'estómago (de un animal)'; rabiza 'timón del arado'; rencollo 'rencoso' ${ }^{17}$. Corresponden, en Canarias, a abanador 'soplillo' (140); abanar 'aventar' (140); alpende 'cubierta volada de cualquier edificio' (132); borralla 'rescoldo' (141); cañoto 'zurdo' (104); cardume 'banco de peces' (272); coruja 'lechuza' (ALEICan, 305); fañoso 'gangoso' (98); fechar 'cerrar' (134); fogaje 'erupción de la piel' (127); gallo 'gajo de la nuez' (205); payo 'estómago del cerdo' (241); rabiza 'mancera del arado' (196); roncollo 'carnero de un solo testículo' $(242)^{18}$. Las correspondencias con Luisiana son mínimas: borralla (con emboralla'o), coruja (con corujo) y fechar.

En suma: Creo que, en su carácter y en su origen, son inconfundibles los lusismos del español de Luisiana. Junto a los típicos canarismos que se documentan, sobre todo en el dialecto isleño ${ }^{19}$, los portuguesismos nos ayudan a confirmar muy a las claras el carácter fundamentalmente canario de los dos

17 Véase Alvar, «Portuguesismos en andaluz», págs. 312-315. También sería interesante comparar el repertorio léxico y las categorias semánticas de los lusismos presentes en otros dialectos españoles muy influidos por el portugués: p. ej., el dialecto fronterizo del Uruguay y el español que se habla en Olivenza y los demás pueblos extremeños de la frontera luso-espan̉ola. Sobre el dialecto uruguayo, véase la breve monografía de Rona (quien se interesa primordialmente por la fonologia) y el folleto de Elizaincín, que conozco sólo mediante un artículo-resefía de R. E. Wood (págs. 243-244). Aunque sea una lengua criolla, el papiamento, con su importante substrato criollo-portugués y su masiva relexificación española, representa básicamente otro caso más de hibridismo luso-español. Véase el artículo de Megenney sobre el «español caribeño»; nótese también su estudio del palenquero.

18 Consigno, a continuación de cada palabra, la página pertinente en PV; donde falta, como para coruja, remito al ALEICan.

19 Como, por ejemplo, beletén 'calostro'; coger la camella 'dejarse aprovechar por otro'; (d)esmayarse 'bostezar'; droga 'deuda'; fuego salvaje 'sarpullido'; gofio 'las clásicas gachas canarias'; guantaso 'bofetada'; guirre 'buitre'; mareta 'estanque pequeño'. Aunque algunas de estas voces no sean exclusivamente canarias, todas son típicas de las Islas. Véanse Millares, mis «Tres dialectos», págs. 289-290, y otros canarismos consignados en la n. 10 (supra). Según me informa Irvan Pérez, ya sólo los más ancianos se acuerdan de haber comido el gofio; dejó de ser costumbre prepararlo en los primeros años de este siglo. 
dialectos, pese a las muchas influencias alienigenas que han experimentado a través de sus diversas aventuras en América.

\section{BIBLIOGRAFIA.}

Acevedo y Huelves, Bernardo, y Fernández y Fernández, Marcelino, Vocabulario del bable de occidente, Madrid, C. E. H., 1932.

Acosta Rodríguez, Antonio, La población de Luisiana española (1763-1803), Madrid, Ministerio de Asuntos Exteriores, 1979.

Alcalá Venceslada, Antonio, Vocabulario andaluz, Madrid, Gredos, 1980.

Alonso, Dámaso, «Junio y julio entre Galicia y Asturias», Obras completas, I: Estudios lingüisticos peninsulares, Madrid, Gredos, 1972, págs. 389-415.

Alvar $=$

ALEICan $=$

«Arabismos» $=$

«Arcaísmos» $=$
Alonso, María Rosa, «Folklore infantil», Museo Canario, 5, 12, 1944, págs. 15-36.

Alvar, Manuel, El español hablado en Tenerife, Madrid, C. S. I. C., 1959.

Alvar, Manuel, «Portuguesismos en andaluz», Weltoffene Romanistik: Festschrift Alwin Kubn zum 60 Geburtstag, ed. Guntram Plangg y Eberhard Tiefenthaler, Innsbruck, Sprachwissenschaftliche Institut der Leopold-Franzens-Universität, 1963, págs. 304-324.

Alvar, Manuel, «Dialectología y cultura popular en las Islas Canarias», Litterae Hispanae et Lusitanae zum fünfzigjäbrigen Bestehen des Ibero-Amerikanischen Forschungsinstituts der Universität Hamburg, ed. Hans Flasche, München, Max Hueber, 1968, págs. 17-32.

Alvar, Manuel, «Sociologia en un microcosmos lingüístico (El Roque de las Bodegas, Tenerife)», Probemio, 2, 1, abril 1971, págs. 5-24.

Alvar, Manuel, Atlas Lingüistico y Etnográfico de las Islas Canarias, 3 tomos, Madrid, Cabildo Insular de Gran Canaria, 1975-1978.

Alvar, Manuel, «Originalidad interna en el léxico canario», I Simposio Internacional de Lengua Española (1978), ed. Manuel Alvar, Gran Canaria, Cabildo Insular, 1981, págs. 225-272.

Alvar, Manuel, «Encuestas en Estados Unidos», LEA, 13, 1991, págs. 273.278.

Álvarez, Guzmán, El habla de Babia y Laciana, Madrid, C. S. I. C., 1949.

Álvarez Delgado, Juan, «Notas sobre el español de Canarias», RDTP, 3, 1947, págs. 205. 235.

Alvarez Nazario, Manuel, La berencia lingüistica de Canarias en Puerto Rico: Estudio bistórico-dialectal, San Juan, Instituto de Cultura Puertorriquenia, 1972.

Pérez Vidal, José, «Arabismos y guanchismos en el español de Canarias», RDTP, 23, 1967, págs. 243-272.

Pérez Vidal, José, «Arcaísmos y portuguesismos en el español de Canarias», Revista de Historia, 29, 1963-1964, págs. 23-37.

Arias, Juan de Dios, «Juegos infantiles», Revista de Folklore, Bogotá, Serie 2, 1952, págs. 111-127.

Armistead, Samuel G., «Romances tradicionales entre los hispanohablantes del estado de Luisiana», Nueva Revista de Filología Hispánica, 27, 1978, págs. $39-56$.

Armistead, Samuel G., «Un corrido de la muerte de Madero cantado en Luisiana», Anuario de Letras, 20, 1982, págs. 379-387.

Armistead, Samuel G., y Monroe, James T., «Albas, Mammas, and Code-Switching in the Kharjas: A Reply to Keith Whinnom», La Corónica, 11, 2, 1982-1983, págs. 174-207.

Armistead, Samuel G., «Más romances de Luisiana», Nueva Revista de Filologia Hispánica, 32, 1983, págs. 41-54. 
Armistead, Samuel G., «Spanish Riddles from St. Bernard Parish», Louisiana Folklore Miscellany, 5, 3, 1983, págs. 1-8.

Armistead, Samuel G., «Adivinanzas españolas de Luisiana», Homenaje a Alvaro Galmés de Fuentes, 2 tomos, Madrid, Gredos, 1985, II, págs. 251-262.

Armistead, Samuel G., y Gregory, Hiram F., «French Loan Words in the Spanish Dialect of Sabine and Natchitoches Parishes», Louisiana Folklife, 10, 1986, págs. 21-30.

Armistead, Samuel G., «Américo Castro in Morocco: The Origins of a Theory? », Américo Castro: The Impact of His Thought: Essays to Mark the Centenary of His Birth, ed. Ronald E. Surtz, Madison, Wisconsin, Hispanic Seminary of Medieval Studies, 1988, págs. 73-82.

Armistead, Samuel G., «The 'Paragogic' - $d$ - in Judeo-Spanish Romances», Hispanic Studies in Honor of Joseph H. Silverman, ed. Joseph V. Ricapito, Newark, Delaware, Juan de la Cuesta, 1988, págs. 57-75.

Armistead, Samuel G., «Más adivinanzas españolas de Luisiana», Homenaje a Alonso Za. mora Vicente, 2 tomos, Madrid, Castalia, 1989, II, págs. 25-38.

Armistead, Samuel G., «Tres dialectos españoles de Luisiana», LEA, 13, 1991, págs. 279. 301.

Armistead, Samuel G., «Vestigios de literatura oral hispánica en dos comunidades de Luisiana», Estudios dedicados al profesor Juan Martinez Ruiz, ed. Juan Paredes Núñez, Granada, Universidad de Granada, 1991, págs. 49-57.

Armistead, Samuel G., «Catalan Children's Games in a Louisiana Spanish Community», Libraries, History, Diplomacy, and the Performing Arts: Essays in Honor of Carleton Sprague Smith, ed. Israel J. Katz, Nueva York, New York Public Library and Pendragon Press, 1991, págs. 115-121.

Attias, Moshe, Romancero sefaradi: Romanzas y cantes populares en judeo-español, 2." ed., Jerusalén, Instituto Ben-Zewi, 1961.

Bächtold-Stäubli, Hanns, y Hoffmann-Krayer, Eduard, Handwörterbuch des deutschen Aberglaubens, 10 tomos, 2.' ed., Berlin-Leipzig, Walter de Gruyter, 1987.

Bartoli, Mateo G., Das Dalmatische, 2 tomos, Viena, Alfred Hölder, 1906.

Baz, José María, El habla de la tierra de Aliste, Madrid, C. S. I. C., 1967.

Benoliel, José, «Dialecto judeo-hispano-marroquí o hakitía», BRAE, 13, 1926, págs. 209. $233,342-363,507-538 ; 14,1927,137-168,196-234,357-373,566-580 ; 15,1928,47-61$, 188-223; 32, 1952, 255-289.

Bonnet, Sergio F., «Familias portuguesas en La Laguna del siglo xvri», Revista de Historia, 17, 1951, págs. 111-118.

Braga, Theðphilo, Cantos Populares do Archipélago Açoriano, Oporto, Livraria Nacional, 1869.

Buesa Oliver, Tomás, «Facetas expresivas en el espafiol de Canarias», II Simposio Interna. cional de Lengua Española (1981), ed. Manuel Alvar, Madrid, Cabildo Insular de Gran Canaria, 1984, págs. 229-251.

Burt, William H., y Grossenheider, Richard P., A Field Guide to the Mammals: Field Marks of All Species Found North of the Mexican Boundary, 2.' ed., Boston, Houghton Mifflin, 1964.

Cadilla de Martínez, María, Juegos y canciones infantiles de Puerto Rico, San Juan, Puerto Rico, Baldrich, 1940.

Câmara Cascudo, Luís da, Dicionário do Folclore Brasileiro, 2." ed., 2 tomos, Rio de Janeiro, Instituto Nacional do Livro, 1962.

Canellada, María Josefa, El bable de Cabranes, Madrid, C. S. I. C., 1944.

Cano González, Ana María, Vocabulario del Bable de Somiedo, Oviedo, I. E. A., 1982. 
Carré Alvarellos, Leandro, Diccionario galego-castelán ..., 3. ed., La Coruña, Roel, 1951.

Casado Lobato, María Concepción, El babla de la Cabrera Alta: Contribución al estudio del dialecto leonés, Madrid, C. S. I. C., 1948.

Catalán, Diego, «El romancero medieval», El comentario de textos, 4: La poesía medieval, Madrid, Castalia, 1983, págs. 451-489.

Cioranescu, Alejandro, Diccionario etimológico rumano, 6 fascículos, La Laguna, Universidad de La Laguna, 1958-1961.

Coelho, Francisco Adolfo, Jogos e rimas infantis, 2.: ed., Oporto, Companhia Portugueza Editora, 1919.

«Comportamiento $=$ Pérez Vidal, José, «Comportamiento fonético de los portuguesismos en Canarias», RDTP, 24, 1968, págs. 219-252.

Conde Saiz, María Victoria, El habla de Sobrescobio, Mieres del Camino, Instituto «Bernaldo de Quirós», 1978.

Corral Díaz, Esther, «Denominacións galegas da curuxa», Verba, 12, 1985, págs. 183-197.

Cuscoy, Luis Diego, Tradiciones populares, II: Folklore infantil, La Laguna de Tenerife, Instituto de Estudios Canarios, 1943.

Daigle, Jules O., A Dictionary of the Cajun Language, Ann Arbor, Michigan, Edwards Brothers, 1984.

$D A R E=\quad$ Cassidy, Frederic G., y Houston Hall, Joan, Dictionary of American Regional English, 2 tomos, Cambridge, Massachusetts, Harvard University Press, 1985-1991.

DCECH = Corominas, Joan, y Pascual, José A., Diccionario crítico etimológico castellano e hispánico, 6 tomos, Madrid, Gredos, 1980-1991.

Di Filippo, M. Alario, Lexicon de colombianismos, Cartagena, Editora Bolívar, 1964.

Din, Gilbert C., The Canary Islanders of Louisiana, Baton Rouge, Louisiana State University Press, 1988.

Eggenschwiler, Emil, Die Namen der Fledermaus auf dem französischen und italienischen Sprachgebiet, Leipzig, C. \& E. Vogel, 1934.

Elizaincín, Adolfo, Algunas precisiones sobre los dialectos portugueses en El Uruguay, Montevideo, Universidad de la República, 1979.

Erich, Oswald A., y Beitl, Richard, Wörterbuch der deutschen Volkskunde, 2.' ed., Stuttgart, Alfred Kröner, 1955.

Fernández Costas, Manuel, «Juegos infantiles en la comarca de Tuy», RDTP, 7, 1952, págs. 633-676.

Figueiredo, Cândido de, Dicionário da Lingua Portuguesa, 14.' ed., 2 tomos, Lisboa, Livraria Bertrand, [1949].

Garasa, Delfín L., «Voces náuticas en Tierra Firme», Filología, 4, 1952-1953, págs. 169209.

García, Constantino, Léxico de la camarca compostelana, Santiago, Universidad de Santiago de Compostela, 1974.

García Mouton $=$ García Mouton, Pilar, «El arco iris: geografía lingǘrstica y creencias populares», RDTP, 39, 1984, págs. 169-190.

García Mouton, Pilar, «El léxico de la Isla del Hierro», RDTP, 46, 1991, págs. 247-264.

Garfias, Carlota, «Mexican Folklore Collected in New York City», Journal of American Folklore, 51, 1938, págs. 83-91.

Garrote, Santiago Alonso, El dialecto vulgar leonés hablado en Maragatería y tierra de Astorga, 2." ed., Madrid, C. S. I. C., 1947.

Hardisson, Emilio, «Las Canarias y Portugal», Boletim Cultural (Câmara Municipal do Pôrto), 10, 1-2, marzo-junio 1947, págs. 165-184.

Harrar, Ellwood S., y Harrar, J. George, Guide to Southern Trees, 2: ed., Nueva York, Dover, 1962. 
Ibn Azzuz Akím, Mohammad, Diccionario de supersticiones y mitos marroquies, Madrid, C. S. I. C., 1958.

Krüger, Fritz, Die Gegenstandskultur Sanabrias und seiner Nachbargebiete: Ein Beitrag zur spanischen und portugiesischen Volkskunde, Hamburg, L. Friederichsen, 1925.

Lamano y Beneite, José de, El dialecto vulgar salmantino, Salamanca, «El Salmantino», 1915.

Leite de Vasconcellos, José, Estudos de Pbilologia Mirandesa, Lisboa, Imprenta Nacional, 1900.

«Léxico $=$

Pérez Vidal, José, «La influencia portuguesa en el léxico vitivinícola de Canarias», RDTP, 43, 1988, págs. 467-476.

Lipski, John M., «El dialecto español de Río Sabinas: Vestigios del español mexicano en Luisiana y Texas», NRFH, 35, 1987, págs. 111-128.

Lipski, John M., The Language of the «Isleños»: Vestigial Spanish in Louisiana, Baton Rouge, Louisiana State University Press, 1990.

Lopes Alves, Joana, A Linguagem dos Pescadores da Ericeira, Lisboa, Junta Distrital, 1965.

Lozoya, Marqués de, «La huella portuguesa en el arte de las Islas Canarias», Colóquio, Lisboa, núm. 57, febrero 1970, págs. 3-9.

Lugo, Sebastián de, Colección de voces y trases provinciales de Canarias, ed. José Pérez Vidal, La Laguna de Tenerife, Universidad de La Laguna, 1946.

Luria, Max, A Study of the Monastir Dialect of Judeo-Spanish Based on Oral Material Collected in Monastir, Yugo-Slavia, Nueva York, Instituto de las Españas, 1930.

Llorente $(\mathrm{I})=\quad$ Llorente Maldonado de Guevara, Antonio, El léxico del tomo I del "Atlas lingüístico y etnográfico de las Islas Canarias», Cáceres, Universidad de Extremadura, 1987.

Llorente (II) $=$

«Lluvia» $=$

$\mathrm{M}=$

Llorente Maldonado de Guevara, Antonio, «Comentario a algunos aspectos del léxico del tomo II del ALEICan», I Simposio Internacional de Lengua Española (1978), ed. Manuel Alvar, Gran Canaria, Cabildo Insular, 1981, págs. 193-224.

Llorente Maldonado de Guevara, Antonio, «Comentario de algunos aspectos del léxico del tomo I del ALEICan», II Simposio Internacional de Lengua Española (1981), ed. Manuel Alvar, Madrid, Cabildo Insular de Gran Canaria, 1984, págs. 283-330.

Pérez Vidal, José, «Nombres de la lluvia menuda en la isla de la Palma (Canarias)», RDTP, 5, 1949, págs. 177-199.

MacCurdy, Raymond R., The. Spanish Dialect in St. Bernard Parish, Louisiana, Albuquerque, University of New Mexico Press, 1950.

MacCurdy, Raymond R., «Louisiana-French Loan-Words for 'Water-Fowl' in the Spanish of St. Bernard Parish, Louisiana», Romance Studies presented to William Morton Dey, ed. Urban T. Holmes et al., Chapel Hill, University of North Carolina, 1950, págs. 137. 142.

MacCurdy, Raymond R., «A Spanish Word-List of the 'Brulis' Dwellers of Louisiana», Hispania, 42, 1959, págs. 547-554.

MacCurdy, Raymond R., «Los "isleños" de la Luisiana: Supervivencia de la lengua y folklore canarios», Anuario de Estudios Atlánticos, 21, 1975, 471-591.

Malaret, Augusto, Vocabulario de Puerto Rico, Nueva York, Las Américas, 1955.

«Marineras» $=\quad$ Pérez Vidal, José, «Influencias marineras en el español de Canarias», RDTP, 7, 1952, págs. 3-25.

Martínez Almoyna, Julio, Dicionário de Portugués-Espanbol, Oporto, Porto Editora, [1959?].

Mathews, Mitford M., A Dictionary of Americanisms on Historical Principles, Chicago, University of Chicago Press, 1956. 
McDermott, John Francis, A Glossary of Mississippi Valley Frencb 1673-1850, St. Louis, Mo., Washington University, 1941.

Megenney, William W., «La influencia del portugués en el palenquero colombiano», BICC, 38, 1983, págs. 548-563.

Megenney, William W., «La influencia criollo-portuguesa en el español caribeño», Anuario de Lingüistica Hispánica, 1, 1985, págs. 157-179.

Melo, Veríssimo de, Folclore Infantil, Río de Janeiro, Cátedra, 1981.

Millares, Luis, y Millares, Agustín, Léxico de Gran Canaria, Las Palmas, Tipografía del «Diario», 1924.

Morais Silva, Antônio de, Grande Dicionário da Lingua Portuguesa, 10." ed., 12 tomos, Lisboa, Confluência, 1949-1959.

Morínigo, Marcos A., Diccionario manual de americanismos, Buenos Aires, Muchnik, 1966.

Moura Santos, Maria José de, Os Falares Fronteiriços de Trás-os-Montes, Coimbra, Universidade, 1967.

Munthe, Ake W., «Folkpoesi från Asturien», Språkvetenskapliga Sällskapets i Upsala Förhandlingar (Sept. 1885-mayo 1888): Upsala Universitets Arskrift: Filosofi, Språkvetenskap och Historiska Vetenskaper, 5, 1887, págs. 105-124.

Navarro Artiles, Francisco, y Calero Carreño, Fausto, «Vocabulario de Fuerteventura», RDTP, 21, 1965, págs. 103-142, 215-272; 22, 1966, págs. 135-199.

Neira Martínez, Jesús, El babla de Lena, Oviedo, I. E. A., 1955.

Opie, Iona, y Tatem, Moira, A Dictionary of Superstitions, Oxford, Oxford University Press, 1989.

Otero, Aníbal, Vocabulario de San Jorge de Piquín, Santiago de Compostela, Universidad de Santiago de Compostela, 1977.

Pérez Vidal, José, «Folklore infantil de las Islas Canarias», RHM, 11, 1945, págs. 349-370.

Pérez Vidal, José, reseña de Raymond R. MacCurdy, The Spanish Dialect in St. Bernard Parish, Louisiana, Albuquerque, University of New Mexico Press, 1950; Revista de Historia, 16, 1950, págs. 418-425.

Pérez Vidal, José, reseña de Raymond R. MacCurdy, The Spanish Dialect in St. Bernard Parish, Louisiana, Albuquerque, University of New Mexico Press, 1950; RDTP, 7, 1951, págs. 158-159.

Pérez Vidal, José, «'Pico, pico, melorico': Un juego infantil en Canarias», Anuario de Es. tudios Atlánticos, 8, 1962, págs. 217-236.

Pérez Vidal, José, Folclore infantil canario, Madrid, Cabildo Insular de Gran Canaria, 1986.

Peterson, Roger Tory, A Field Guide to the Birds of Texas and Adjacent States, Boston, Houghton Mifflin, 1963.

Pires de Lima, Joaquim Alberto, «A Alma de Portugal na sua Passagem para o Brasil», RDTP, 4, 1948, págs. 365-386.

Porto Dapena, J. Alvaro, El gallego bablado en la comarca ferrolana, Santiago de Compostela, Universidad de Santiago de Compostela, 1977.

«Provincialismos» $=$ Pérez Vidal, José, «Los provincialismos canarios del Diccionario de la Academia», RHM, 13, 1947, págs. 130-158.

$\mathrm{PV}=$

Pérez Vidal, José, Los portugueses en Canarias: Portuguesismos, Las Palmas, Cabildo Insular de Gran Canaria, 1991.

Quiben, Víctor Lis, La medicina popular en Galicia, Pontevedra, Gráficas Torres, 1949.

Radford, E. y M. A., y Hole, Christina, Encyclopedia of Superstitions, [2." ed.], Londres, Hutchinson, 1980.

Read, William A., Louisiana French, Baton Rouge, Louisiana State University Press, 1931. 
Ricard, Robert, «Relaciones entre Canarias y las plazas portuguesas de Marruecos en el siglo XVI», Revista de Historia, 15, 1949, págs. 5-13.

Ríos Panisse, Marfa del Carmen, Nomenclatura de la flora y fauna maritimas de Galicia, 2 tomos, Santiago, Universidad de Santiago, 1977-1983.

Rodríguez-Castellano, Lorenzo, Aspectos del bable occidental, Oviedo, I. E. A., 1954.

Rodríguez-Castellano, Lorenzo, Contribución al vocabulario del bable occidental, Oviedo, I. E. A., 1957.

Rona, José Pedro, El dialecto «fronterizo» del norte del Uruguay, Montevideo, Adolfo Linardi, 1965.

Sala, Marius, Phonétique et phonologie du judéo-espagnol de Bucarest, La Haya-Paris, Mouton, 1971.

Sánchez Pérez, José A., Supersticiones españolas, Madrid, S. A. E. T. A., 1948.

Sanchís Guarner, Manuel, «Nombres del murciélago en el dominio catalán», RFE, 40, 1956, págs. 91-125.

Sánchez Vicente, Xuan Xosé, Diccionariu de la llingua asturiana, Gijón, González y Huici, 1988.

Santamaría = Santamaría, Francisco J., Diccionario general de americanismos, 3 tomos, México, Pedro Robredo, 1942.

Santamaría, Francisco J., Diccionario de mejicanismos, 4." ed., México, Porrúa, 1983.

Stark, Louisa, «Notes on a Dialect of Spanish Spoken in Northern Louisiana», Anthropological Linguistics, 22, 1980, págs. 163-176.

$S T=$

*Toponimia* $=$

Armistead, Samuel G., The Spanish Tradition in Louisiana, I: Isleño Folkliterature, transcripciones musicales de Israel J. Katz, Newark, Delaware, Juan de la Cuesta, 1992.

Taboada, Manuel, El habla del Valle de Verin, Santiago de Compostela, Universidad de Santiago de Compostela, 1979.

Taylor, James L., A Portuguese-English Dictionary, Stanford, Stanford University Press, 1958.

Pérez Vidal, José, «Influencia portuguesa en la toponimia canaria», RDTP, 20, 1964, págs. $255 \cdot 270$.

Vedia, Enrique de, y Morón, Guillermo (ed.), Historiadores primitivos de Indias, 3 tomos, Madrid, Atlas, 1946-1965.

Viera y Clavijo, José de, Diccionario de bistoria natural de las Islas Canarias, ed. Manuel Alvar, Madrid, Mancomunidad de Cabildos de Las Palmas, 1982.

Vigón, Braulio, Vocabulario dialectológico del concejo de Colunga, ed. Ana Vigón Sánchez, Madrid, C. S. I. C., 1955.

Viudas Camarasa, Antonio, Diccionario extremeño, Cáceres, Universidad de Extremadura, 1980.

Wagner, Max Leopold, Beiträge zur Kenntnis des Judenspanischen von Konstantinopel, Viena, Alfred Hölder, 1914.

Wagner, Max Leopold, reseña de Luis y Agustín Millares, Léxico de Gran Canaria, Las Palmas, Tipografía del «Diario», 1924, RFE, 12, 1925, págs. 78-86.

Wagner, Max Leopold, Sondersprachen der Romania, ed. Heinz Kröll, 4 tomos, Stuttgart, Franz Steiner, 1990.

Walls, Jerry G., Fishes of the Northern Gulf of Mexico, Neptune City, New Jersey, T. F. H. Publications, 1975.

Westermarck, Edward, Ritual and Belief in Morocco, 2 tomos, New Hyde Park, Nueva York, University Books, 1968.

Whinnom, Keith, A Glossary of Spanish Bird-Names, Londres, Támesis, 1966.

Wood, Richard E., «Current Sociolinguistics in Latin America», Latin American Research Review, 16, 1, 1981, págs. 240-251. 